\title{
Sebastian Brants Übertragung des Mariengrußes Ave, salve, gaude, vale und ihre Aneignung durch den Basler Kartäuser Ludwig Moser
}

\section{Brant oder Moser? Zum Problem der Urheberschaft}

Wer sich in Philipp Wackernagels Edition volkssprachlicher geistlicher Lieder über das lyrische Schaffen des Basler Kartäusers Ludwig Moser (1442-1510) informieren möchte, wird im zweiten Band der umfangreichen Anthologie fündig. Unter den Nummern 1070-1074 sind unter Mosers Namen zunächst vier Hymnenübertragungen abgedruckt; ${ }^{1}$ ihnen folgt eine Adaptation des 50strophigen Mariengrußes Ave, salve, gaude, vale, der auch unter dem Titel Crinale B. M. V. bekannt ist und von dem Kartäuser Konrad von Haimburg († 1360) geschaffen wurde. ${ }^{2}$ Der Wiedergabe der fünf Texte geht folgende Quellenangabe voraus: „Die Lieder stehen im Anhange zu dem Buche Der guldin Spiegel des Sunders. Basel 1497. $8^{\circ}$ “" 3 Es handelt sich um eine in der Offizin des Basler Druckers Johannes Amerbach erschienene, von Ludwig Moser betreute Inkunabel, ${ }^{4}$ die aus zwei drucktechnisch voneinander unabhängigen, jedoch meist im Überlieferungsverbund tradierten Teilen besteht: ${ }^{5}$ einem - aus mehreren Prosaübertragungen zusammengefügten - Hauptteil und einem Anhang, der die von Wackernagel

1 Vgl. Wackernagel 2, S. 869-872. Es handelt sich um volkssprachliche Aneignungen folgender Texte: Verbum supernum (AH 50, S. 588f., Nr. 388), Ave vivens hostia (AH 31, S. 111-114, Nr. 105), Pange lingua (AH 50, S. 586f., Nr. 386) sowie Veni creator spiritus (AH 50, S. 193f., Nr. 144).

2 Das Crinale B. M. V. ist ediert in AH 3, S. 22-26, Nr. 2. Siehe zur Moser zugeschriebenen volkssprachlichen Adaptation Wackernagel 2, S. 872-875.

3 Vgl. Wackernagel 2, S. 869.

4 Jacobus van Gruytrode: Speculum aureum animae peccatricis, deutsch, etc. Übers. Ludwig Moser. Basel: [Johannes Amerbach], 1497. Siehe GW, Nr. 13866. Die Offizin ist nachträglich erschlossen, zählt Johannes Amerbach doch zu jenen Basler Druckern, die zwar volkssprachliche Werke in ihr Verlagsprogramm aufnehmen, diese jedoch grundsätzlich nicht mit ihrem Namen signieren. Vgl. Günthart, S. 26.

5 Vgl. Honemann, S. 154; Günthart, S. 100.

○ OpenAccess. (C 2020 Lydia Wegener, publiziert von De Gruyter. (cc))BY Dieses Werk ist lizenziert unter der Creative Commons Attribution 4.0 International. https://doi.org/10.1515/9783110666816-014 
edierten Liedübersetzungen enthält. ${ }^{6}$ Wackernagels summarische Auskunft zu der von ihm verwendeten Quelle unterschlägt allerdings die unterschiedliche Darbietung der Texte: Während die vier Hymnenübertragungen integraler Bestandteil eines Cursz vom sacrament sind und daher im Inhaltsverzeichnis des Anhangs nicht gesondert aufgeführt werden, kommt der Crinale-Adaptation eine Sonderstellung zu. Nicht nur wird sie als dritter und letzter Text unter dem Titel Sant Bernarts Rosenkrantz extra angekündigt, ${ }^{7}$ die Vorrede zum Appendix hebt ihre Bedeutung als finales Marienlob zusätzlich hervor. ${ }^{8}$ Damit avanciert die Crinale-Übertragung zum Schluss- und Höhepunkt nicht nur des Anhangs, sondern der Gesamtpublikation. ${ }^{9}$

Das Interesse des vorliegenden Beitrages gilt dieser Mariengruß-Dichtung, und zwar nicht allein wegen ihrer herausgehobenen Position im Guldin Spiegel des Sunders, sondern auch und vor allem wegen ihrer Überlieferung in mehreren Versionen, die neben Moser einen weiteren prominenten Namen ins Spiel bringen.

Denn Wackernagels Einordnung des volkssprachlichen Crinale unter die Werke Ludwig Mosers stieß rasch auf entschiedenen Widerspruch. Bereits 1875 acht Jahre nach der Publikation des zweiten Bandes von Wackernagels Anthologie - stellt Karl Schmidt fest, dass die Übertragung keineswegs als Schöpfung des Basler Kartäusers gelten könne. Vielmehr handele es sich um eine Dichtung des Juraprofessors und Poetik-Dozenten Sebastian Brant, dessen namentlich signiertes Autograph in einem Basler Codex enthalten sei. Diesen Text habe eine fremde Hand mit einigen Änderungen versehen, bevor ihn Moser ohne Hinweis

6 Siehe zu den Bestandteilen des Guldin Spiegel weiter unten, Abschnitt 5.3, S. 254.

7 Vgl. im online zugänglichen Digitalisat des Anhangs (Basel, UB, FP VI 15:1/3) fol. $1^{\mathrm{r}}$. Hier und im Folgenden entspricht die Blattzählung in Hauptteil und Anhang der modernen Bleistiftfoliierung. Die Zuweisung des Crinale an Bernhard von Clairvaux ist zu Mosers Zeit üblich. Vgl. Worstbrock, Sp. 183; Knape, S. 320, Anm. 53. Siehe auch das Zitat in der folgenden Anmerkung.

8 Guldin Spiegel (Anhang), fol. $2^{\mathrm{v}}$ : Vnd zu lest das wirdig lob der iungfrowen Marie gotz muiter durch sant Bernart gedichtet / on die keyn gnad geben / eruolgt / oder bliplich mag sin zu danck gesetzt. Für alle mittelhochdeutschen Zitate gilt hier und im Folgenden eine zeichengenaue Wiedergabe. Verschiedene Buchstabenformen wie $\int$ und $s$ werden allerdings einheitlich in der heute üblichen Form (in diesem Fall: $s$ ) wiedergegeben und Abbreviaturen sind konsequent aufgelöst.

9 Dies gilt allerdings nur für die mehrheitlich überlieferten Spiegel-Exemplare, die aus Hauptteil und Anhang bestehen. Aufgrund seiner drucktechnischen Unabhängigkeit konnte der Hauptteil auch ohne Appendix vertrieben werden. Siehe zu den erhaltenen Drucken Günthart, S. 338-340. Offenbleiben muss einstweilen die Frage, ob auch der Anhang - der kein Kolophon beinhaltet gesondert erhältlich war. Schmidt spricht 1875 zwar von einem „kleinen Buch“, welches die Mariengruß-Dichtung enthalte und „auch“ als Anhang zum Spiegel des Sunders überliefert sei; er gibt jedoch keine Auskunft über die von ihm eingesehenen (und möglicherweise inzwischen verschollenen) Exemplare. Vgl. Schmidt, S. 46. 
auf den berühmten Urheber veröffentlichte. ${ }^{10}$ Um hinsichtlich der verschiedenen Versionen der Crinale-Adaptation eine Vergleichsmöglichkeit $\mathrm{zu}$ bieten, gibt Schmidt Brants Autograph vollständig wieder. In einem Apparat ergänzt er sowohl die Eingriffe in die Handschrift als auch die darüber hinausgehenden Varianten der gedruckten Version. ${ }^{11}$

Aus Schmidts Ausführungen und seiner Edition geht eindeutig hervor, dass die deutsche Adaptation von Ave, salve, gaude, vale in drei Versionen existiert: 1. Das Original stammt von Sebastian Brant. Ergänzend zu Schmidt sei bemerkt, dass die eigenhändige Niederschrift Brants in Cod. A IX 27 der Universitätsbibliothek Basel zu finden ist, ${ }^{12}$ einer Sammelhandschrift aus dem Besitz der Basler Kartause St. Margarethental. ${ }^{13}$

2. Die „Aenderungen von anderer Hand“ ${ }^{\prime 14}$ stammen von Ludwig Moser, ${ }^{15}$ der in Brants Text verschiedentlich inhaltlich und formal eingegriffen hat. Diese Modifikationen bleiben allerdings so dezent, dass von einer konsequenten Umformung der Ursprungsversion nicht die Rede sein kann. Das Resultat ist daher keine eigenständige Fassung, wohl aber eine Bearbeitung des Brantschen Autographs. ${ }^{16}$

3. Von dieser zurückhaltenden Abwandlung des originalen Wortlauts unterscheidet sich die zum Druck gelangte Version der Mariengruß-Dichtung eklatant. Hier artikuliert sich durchgängig ein eigenständiger „Formulierungs- und Gestaltungswille“ ${ }^{17}$ der Brants Übertragung zwar nicht vollständig verdrängt, aber gleichwohl eine neue Textfassung hervorbringt.

Der autonome Status dieser Fassung findet in der nach Schmidts Einlassung entstehenden Forschung allerdings keine Resonanz. Stattdessen erfolgt in den wenigen Beiträgen, die sich mit der Crinale-Übertragung beschäftigen, in unter-

10 Vgl. Schmidt, S. $45 \mathrm{f}$.

11 Vgl. ebd., S. 46-60.

12 Das Autograph befindet sich auf fol. $195^{\mathrm{r}}-202^{\mathrm{v}}$. Bereits Binz weist in seiner Handschriftenbeschreibung (1907) auf den Eintrag Brants hin. Vgl. ebd., S. 136. Siehe ferner Honemann, S. 200. 13 Siehe zur Provenienz Binz, S. 133; Honemann, S. 198.

14 Schmidt, S. 46.

15 Vgl. Honemann, S. 200; Worstbrock, Sp. 187; Knape, S. 320, Anm. 55; Günthart, S. 102.

16 In Anlehnung an Bumkes Differenzierung verstehe ich unter einer Fassung eine Textversion, die im Vergleich zu anderen Versionen so frei gestaltet ist, dass sie „Merkmale der Originalität“ (Bumke, S. 46) aufweist. Im Unterschied dazu bezeichne ich als Bearbeitung eine Textversion, die aus sporadischen formalen und semantischen Eingriffen in einen vorgängigen Text resultiert, ohne dass diese dem Gesamttext eine neue Prägung verleihen. Vgl. zu den terminologischen Diskussionen um den Fassungsbegriff zusammenfassend Rothenberger, S. 64-68.

17 Bumke, S. 32. 
schiedlicher Weise eine Nivellierung oder zumindest Verwischung der Differenzen zwischen den drei Versionen. Für diese Tendenz gibt es mehrere Gründe: Bei der gedruckten Fassung handelt es sich - wie bereits erwähnt - insofern um ein hybrides Erzeugnis, als sie Brants ursprünglichen Text nicht vollständig ersetzt. Vielmehr werden einzelne Wörter, ganze Verse, aber auch mehrere komplette Strophen aus der vorgängigen Version übernommen. ${ }^{18}$ Dies lässt es naheliegend erscheinen, die gedruckte Fassung ebenfalls als Werk Brants auszuweisen. ${ }^{19}$ Die Aufnahme der Adaptation in den von Moser betreuten Guldin Spiegel kann umgekehrt dazu verleiten, die Mariengruß-Dichtung ausschließlich dem Basler Kartäuser zuzuerkennen. ${ }^{20}$ Diese Entscheidung entweder für den einen oder den anderen Urheber wird dadurch erleichtert, dass die Druckfassung - anders als die Handschrift - auf eine explizite Autorennennung verzichtet. Diese Leerstelle führt außerdem dazu, dass neuere Forschungsbeiträge zwar auf die Eingriffe Mosers in Brants Autograph und ebenso auf deren Übernahme in den Druck hinweisen. Die weit darüber hinausgehenden, namentlich nicht deklarierten Änderungen der gedruckten Version werden jedoch entweder verschwiegen, ${ }^{21}$ in ihrer Relevanz minimiert ${ }^{22}$ oder als Faktum konstatiert, ohne die Frage nach ihrem möglichen Urheber oder zumindest nach ihrer Transformationsleistung im Verhältnis zu Brants Adaptation zu stellen. ${ }^{23}$

Die folgenden Ausführungen werden sich auf die beiden zuletzt genannten Problemstellungen konzentrieren. Ihnen liegt die These einer schrittweisen Aneignung von Brants Crinale-Adaptation durch Ludwig Moser zugrunde. Dieser

18 Siehe dazu auch weiter unten, Abschnitt 5.5, S. 264.

19 Wilhelmi, der in die ,Kleinen Texte' Sebastian Brants sowohl die handschriftliche Fassung (deren Korrekturen im Apparat gesondert aufgeführt werden) als auch die Druckversion aufgenommen hat, geht davon aus, dass Letztere „wohl von Brant selber besorgt“ worden ist. Siehe Brant: Kleine Texte, Bd. 2, S. 28, Nr. 69. Die handschriftliche Fassung ist ediert in Brant: Kleine Texte, Bd. 1.1, S. 68-78, Nr. 69. Zur gedruckten Fassung siehe Brant: Kleine Texte, Bd. 1.2, S. 342351, Nr. 198.

20 Vgl. Appelhans, S. 40f. Die vorgängige Handschrift nimmt Appelhans nicht zur Kenntnis. 21 So schreibt Honemann, S. 155, zur Integration der Crinale-Übertragung in den Guldin Spiegel: „Das Werk wurde hier unter die Moser-Übersetzungen aufgenommen, weil Moser Brants Übersetzung korrigierte; die Korrekturen stehen in D 80/17 [= Text 17 in Hs. D 80, moderne Signatur: A IX 27] und wurden in den Druck aufgenommen.“

22 Siehe dazu etwa den Verfasserlexikon-Artikel von Worstbrock, in dem zunächst auf Mosers Einträge in Brants Autograph hingewiesen wird. Im Anschluss heißt es (Sp. 187): „Mit diesen und anderen Veränderungen ging Brants Übersetzung dann anonym in den Basler Druck ein.“ Unerwähnt bleibt die fassungskonstituierende Bedeutung dieser ,anderen Veränderungen“.

23 So beschränkt sich Knape, S. 320, auf die Feststellung: „Die überlieferten Fassungen A [Handschrift] und b [Druck] weichen in verschiedenen Strophen beträchtlich voneinander ab.“ Vgl. zudem Günthart, S. 102. 
sieht - so die Überlegung - seine eigenen, sowohl durch sein monastisches Umfeld als auch durch seinen spezifischen Vermittlungsanspruch bestimmten Kriterien einer adäquaten Übertragung ${ }^{24}$ durch Brants freie Aneignung des lateinischen Prätextes verletzt. Aus seinen Bemühungen, die handschriftliche Vorlage seinen Vorstellungen entsprechend umzuändern, ohne Brants Formschema aufzugeben, erwachsen paradoxerweise jedoch neue Gestaltungsspielräume. In ihrer Füllung artikuliert sich nun seinerseits ein poetisches Selbstbewusstsein Mosers, das in unauflöslicher Spannung zu seinen Äquivalenzkriterien steht. $^{25}$

Im Einzelnen gliedert sich die Argumentation in folgende Punkte: Zur Kontextualisierung der Crinale-Übertragung widmet sich Abschnitt 2 zunächst der Basler Kartause als Produktions- und Pflegestätte geistlicher Literatur in der Volkssprache. In diesem Zusammenhang werden die Ausführungen in aller Kürze Sebastian Brants Verbundenheit mit der Kartause thematisieren und Ludwig Mosers schriftstellerisches Profil skizzieren. Abschnitt 3 stellt Konrads von Haimburg Mariengruß-Dichtung Ave, salve, gaude, vale formal und inhaltlich vor. Der vierte Abschnitt widmet sich der Überlieferung (4.1) sowie dem poetischen Anspruch und inhaltlichen Profil (4.2) von Brants Übertragung. Danach verfolgt Abschnitt 5 die schrittweise Aneignung der Adaptation durch Ludwig Moser (5.15.4) und erschließt die Transformationsleistung der in den Druck gelangten Fassung im Vergleich zu Brants Ursprungsversion (5.5). Der Beitrag schließt mit einem Fazit (6.), das Mosers Aneignungsverfahren in einen größeren Zusammenhang einzuordnen versucht.

Anzumerken ist, dass den Ausführungen aufgrund von Überlieferungslücken $^{26}$ und der Anonymität der gedruckten Crinale-Adaptation ein thesenhafter Status zukommt.

24 Im Rückgriff auf die Terminologie Albrechts, S. 76, verstehe ich hier und im Folgenden unter ,Adäquatheit' die Relation zwischen einem Text und dessen ,Umfeld', in diesem Fall: zwischen der Crinale-Übertragung, ihrem ,Aneigner` Ludwig Moser und den intendierten Adressaten seiner Publikationen.

25 Unter, Äquivalenz‘ verstehe ich hier und im Folgenden mit Albrecht die Erfüllung jener Invarianzforderungen, die ein Übersetzer in Abhängigkeit von seinen Adäquatheitskriterien erhebt. Dazu zählen z. B. ,Inhalt‘, ,Stil‘ oder ,Wirkung auf den Empfänger‘. Anders als die Adäquatheit (vgl. Anm. 24) bezieht sich die Äquivalenz also auf das Verhältnis zwischen einem Text und dessen (vollständiger oder auszugsweiser) Übersetzung. Vgl. Albrecht, S. $75 \mathrm{f}$.

26 Siehe dazu oben, Anm. 9, sowie weiter unten, Abschnitt 4.1, S. 242. 


\title{
2 Die Basler Kartause als Produktions- und Pflegestätte geistlicher Literatur in der Volkssprache
}

In Sebastian Brants berühmter, vff die Vasenaht $1494^{27}$ erschienener Satire Das Narren Schyff trägt das 105. Kapitel den Titel Hyndernys des gutten. ${ }^{28}$ In ihm kommen jene Narren zu Wort, welche die vita contemplativa der eremitisch lebenden, über weiteste Strecken ihres Daseins schweigenden Kartäuser keineswegs als lobenswürdige Weltabkehr, sondern vielmehr als Verweigerung gegenüber seelsorgerlichen Verpflichtungen wahrnehmen. Die entsprechende Beschwerde über einen solchen duckelmuser (V. 19) lautet:

\author{
Er möcht noch jnn der welt han gthon \\ Vil guitts / vnd hett noch grossern lon \\ Entpfangen / hett er vil gelert \\ Vnd vff den weg der sellikeyt kert \\ Dann das er do lyt wie eyn schwyn \\ Vnd mo̊ßst sich jn der zellen syn. \\ [...] \\ Solt / wie er duit / důn yederman \\ Jn der Chartuß die kutten an \\ Wer woltt die weltt dann fürbas meren \\ Wer wolt die lüt wysen / vnd leren. (V. 35-46)
}

Dieses Zerrbild des pflichtvergessenen, sich in seiner Zelle mästenden Kartäusers muss zumindest den literarisch gebildeten Baslern und Baslerinnen absurd und damit wahrhaft närrisch erschienen sein. Zwar war die konsequente Weltabgeschiedenheit genuiner Bestandteil kartäusischer Spiritualität, ${ }^{29}$ doch bedeutete sie keineswegs einen Verzicht auf seelsorgerliche Aktivität. Diese kam zwar nicht im gesprochenen Wort zum Ausdruck, sehr wohl aber im geschriebenen. Bereits die zwischen 1121 und 1128 unter Guigo I., dem fünften Prior der Grande Chartreuse, kodifizierten Consuetudines der Kartäuser sehen vor, dass jedes Zellenhäuschen mit den Utensilien eines Skriptoriums ausgestattet wird. ${ }^{30}$

27 Vgl. die Datumsangabe im Kolophon (Brant: Das Narrenschiff, S. 511).

28 Vgl. Brant: Das Narrenschiff, S. 479-482.

29 Siehe zur charakteristischen Verbindung von eremitischer und zönobitischer Lebensweise im Kartäuserorden Honemann, S. 8.

30 Vgl. Gilomen-Schenkel: Die Kartause, S. 147. Programmatisch formuliert das 28. Kapitel der Consuetudines die Aufgabe des Kartäusers, Bücher zu schreiben, ut quia ore non possumus, Dei verbum manibus predicemus. Zitiert nach Honemann, S. 10. Vgl. auch Kleineidam, S. 186. 
Die in den Ordensbestimmungen verankerte Affinität der Kartäuser zum Buch findet in der Basler Kartause St. Margarethental einen sehr konkreten Ausdruck. Nach anfänglichen Schwierigkeiten, sich im klösterlichen Gefüge Basels zu etablieren, erlebte das 1401 gegründete Kloster mit dem langjährigen Basler Konzil seinen ersten Aufschwung. ${ }^{31}$ Sein eigentlicher Zenit war aber erst am Ende des fünfzehnten Jahrhunderts erreicht, als der gelehrte Prior Jakob Louber zugleich als Bibliothekar der Kartause wirkte und in den beiden Dekaden zwischen 1480 und 1500 für einen enormen Zuwachs an Büchern sorgte. Unter seiner Ägide erweiterte sich der Buchbestand um gut 1200 Bände und wurde zudem neu systematisiert. ${ }^{32}$ Die geballte Sammlung gelehrten Wissens, welche die Basler Kartäuserbibliothek $\mathrm{zu}$ bieten hatte, steigerte nicht nur ihre Attraktivität für die akademische und humanistische Bildungselite. ${ }^{33}$ Die Zunahme der verfügbaren Schriften intensivierte auch die Kooperation der Kartäuser mit dem lokalen Druckgewerbe, die bereits in der Frühzeit des Basler Buchdrucks mit dem Prior Heinrich Arnoldi von Alveld ihren Anfang genommen hatte. ${ }^{34}$

Dominante Gestalt unter den Gelehrten, die sich von St. Margarethental angezogen fühlten, war der Theologe und Seelsorger Johannes Heynlin von Stein, der nach einer internationalen akademischen Karriere und einer langjährigen Tätigkeit als Prediger unter anderem am Basler Münster 1487 in die Kartause eintrat, in der er 1496 starb. ${ }^{35}$ Auch als Kartäuser blieb Heynlin Mittelpunkt eines ebenso humanistisch wie religiös ausgerichteten Kreises, dem beispielsweise Johannes Reuchlin, Jakob Locher, Jakob Wimpfeling, Johannes Amerbach und Sebastian Brant angehörten. Insbesondere die enge Beziehung Heynlins zu Brant hebt der Kartäuserchronist Georg Carpentarius im vierten Kapitel seiner Continuatio chronicorum Carthusiae in Basilea minori hervor. ${ }^{36}$ Zusammen mit Heynlin

31 Vgl. Sexauer, S. 105f.; Honemann, S. 12; Wilhelmi: Humanistische Gelehrsamkeit, S. 21-23. Siehe zur Geschichte des Basler Kartäuserklosters außerdem die konzise Darstellung von Gilomen-Schenkel: Basel, S. 57-73.

32 Vgl. Sexauer, S. 110; Honemann, S. 13-15; Burckhardt: Bibliotheksaufbau, S. 35f.; GilomenSchenkel: Basel, S. 83.

33 Vgl. Burckhardt: Bibliotheksaufbau, S. 44 f.; Halporn, S. 241; Wilhelmi: Humanistische Gelehrsamkeit, S. $25 \mathrm{f}$.

34 Vgl. Günthart, S. 14; Gilomen-Schenkel: Bücher, S. 18; dies.: Die Kartause, S. 150.

35 Vgl. Günthart, S. 20; Gilomen-Schenkel: Bücher, S. 15f.; dies.: Die Kartause, S. 149f.; Hamm, S.15f., S. 32. Heynlin bereicherte die Mönchsbibliothek der Basler Kartause um fast 300 Bände aus seinem Privatbesitz, von denen 259 Bücher (vorwiegend Frühdrucke) erhalten sind. Vgl. Wilhelmi: Humanistische Gelehrsamkeit, S. 24; Gilomen-Schenkel: Bücher, S. 15. Siehe zum Inkunabelbesitz Heynlins zudem die Auflistung Buckhardts (Die Inkunabeln) nach Signaturen und Titeln.

36 Das Kapitel trägt die Überschrift De vita, conversatione, scriptis et obitu egregii domini Joannis de Lapide sacrae paginae doctoris (Die Chroniken, S. 342) und enthält folgenden Passus: Item alios 
gab Brant 1492 bei Amerbach die gesamten Werke des Kirchenvaters Ambrosius heraus; ${ }^{37}$ zudem hatte er Zugang zur Mönchsbibliothek der Kartäuser, aus der er sich in den 1490er Jahren verschiedene - insbesondere marianische - Werke entlieh. ${ }^{38}$

Neben der lateinisch ausgerichteten Mönchsbibliothek beherbergte St. Margarethental eine volkssprachliche Laienbibliothek, ${ }^{39}$ die vor allem für die ordensrechtlich als ,Laien' geltenden Angehörigen der Kartause bestimmt war. ${ }^{40}$ Aufbewahrt wurden die Bücher zum größten Teil in einem Schrank im Schlafsaal der Laienbrüder, dessen Beaufsichtigung in die Zuständigkeit des cellerarius fiel. ${ }^{41}$ Inhaltlich repräsentiert die Laienbibliothek vor allem die Verehrung der Gottesmutter und ihres Sohnes; ${ }^{42}$ insbesondere die marianische Literatur nimmt breiten Raum ein. Die Laienbibliothek wuchs ebenfalls stetig an, dies vor allem durch die Schenkungen ortsansässiger Drucker. ${ }^{43}$ Diese Gaben hatten einerseits den Charakter heilssichernder Stiftungen, ${ }^{44}$ dienten andererseits aber auch als Ersatz für Handschriften, welche die Kartause als Druckvorlage zur Verfügung gestellt hatte. ${ }^{45}$ Zudem revanchierten sich die Drucker auf diese Weise für die Zusammenarbeit mit Angehörigen der Kartause. Im volkssprachlichen Bereich gilt dies vor

quoque domui conciliavit amicos et fautores, nempe dominum Sebastianum Brant, qui in gratiam ipsius multa carmina devota composuit et in commendationem ordinis Carthusiensis etc. (ebd., S. 345). Brants Verbundenheit mit der Basler Kartause findet in seiner Kartäuser-Ode literarischen Ausdruck. Siehe dazu Stieglecker, S. 339-368; Wilhelmi: Humanistische Gelehrsamkeit, S. 26. 37 Vgl. Wilhelmi: Humanistische Gelehrsamkeit, S. 26.

38 Vgl. Knape, S. 315.

39 Einen ersten Rekonstruktionsversuch der Basler Laienbibliothek hat Sexauer (ebd., S. 160172) unternommen. Auf seinen Erkenntnissen baut die umfangreiche Studie Honemanns zum ursprünglichen Bücherbestand dieser ausschließlich deutschsprachige Texte enthaltenden Bibliothek auf.

40 Vgl. Honemann, S. 22f.

41 Vgl. ebd., S. 20.

42 Vgl. ebd., S. 223.

43 Dementsprechend nimmt Honemann an, dass die ursprünglich ca. 200 Bände umfassende Laienbibliothek vorwiegend Drucke enthielt. Vgl. ebd., S. 24-26. Insbesondere pflegten Johannes Amerbach - in dessen Offizin auch der Guldin Spiegel gedruckt wurde - und seine Familie eine enge geistliche Beziehung zur Basler Kartause. Vgl. Sexauer, S. 107. Explizit verleiht Amerbach seiner Verehrung für den Kartäuserorden im Kolophon des ersten Drucks der Ordensstatuten Ausdruck. Vgl. Statuta ordinis cartusiensis (Basel 1510; VD 16: G 4071), fol. 48v. Siehe auch Blüm, S. 49; Gilomen-Schenkel: Bücher, S. 22.

44 Vgl. Burckhardt: Bibliotheksaufbau, S. 45. Verzeichnet sind die Bücherspenden im Liber benefactorum der Kartause. Vgl. Honemann, S. 21. Siehe zu Amerbachs Schenkungen GilomenSchenkel: Bücher, S. 18-22, sowie S. 28-37. Das Ausleihbuch der Kartause dokumentiert im Gegenzug die Ausleihen Amerbachs. Vgl. Burckhardt: Bibliotheksaufbau, S. 45; Günthart, S. 124. 45 Vgl. Burckhardt: Bibliotheksaufbau, S. 45. 
allem für die Aktivitäten Ludwig Mosers, der Volker Honemann zufolge als „der literaturgeschichtlich bedeutendste Basler Kartäuser“ gelten darf. ${ }^{46}$ Moser, der seine Tätigkeit als Stadtschreiber von Rheinfelden aufgegeben hatte, um 1474 in die Basler Kartause einzutreten, tat sich als ausgesprochen produktiver Autor, Übersetzer und Herausgeber geistlicher Literatur in der Volkssprache hervor. ${ }^{47}$ Vorrangig war er im Bereich der Prosa-Übertragungen aktiv; hier konzentrierte er sich insbesondere auf Werke, die von Bonaventura, Augustinus und Bernhard von Clairvaux verfasst worden waren oder diesen Kirchenschriftstellern zu seiner Zeit zumindest zugeschrieben wurden. ${ }^{48}$

Sebastian Brant und Ludwig Moser haben nicht nur ihre Verbundenheit mit der Basler Kartause und ihr Interesse für volkssprachliche Literatur gemeinsam, sie teilen auch ihre Vorliebe für marianische Themen. ${ }^{49}$ Ungemein populär war in ihrer unmittelbaren Umgebung das Rosenkranzgebet, ${ }^{50}$ um dessen Ausgestaltung sich vor allem die Trierer Kartäuser Adolf von Essen († 1439) und Dominikus von Preußen († 1460) verdient gemacht hatten..$^{51}$ Die Laienbibliothek der Basler Kartause war mit Rosenkranz-Literatur gut bestückt, unter anderem standen den

46 Honemann, S. 145. Siehe zu Mosers Biografie Haeller, S. 11-24. Vgl. außerdem Sexauer, S. 140 f. 47 Die kontinuierliche Zusammenarbeit Ludwig Mosers mit den Basler Druckern nahm spätestens gegen Ende der 1480er Jahre ihren Anfang und währte zwei Jahrzehnte bis zu Mosers Tod.Vgl. Günthart, S. 95. In erster Linie fungierte Moser als Übersetzer und Herausgeber; eigene Schriften sind von ihm nur vereinzelt überliefert. Vgl. ebd., S. 43, S.102. Siehe zu Mosers Schaffen auch ebd., S. 136-144.

48 Vgl. zum Beispiel die siebzehn geistlichen Traktate des sog. ,Ludwig Moser-Büchleins', das in den Jahren 1506 und 1507 beim Basler Drucker Michael Furter erschien. Der erste Band der zweibändigen Anthologie beginnt mit einem Marie Spiegel Sant Bonauenture (Titelblatt); tatsächlich handelt es sich um eine Übertragung des Speculum beatae Mariae virginis Konrads von Sachsen. Vgl. Honemann, S. 152. Siehe zum ,Ludwig Moser-Büchlein‘ auch Günthart, S. 42f., S. 102-111.

49 Günthart, S. 131, weist darauf hin, dass in Basel „auffallend viele deutschsprachige Texte gedruckt wurden, in deren Zentrum die Gottesmutter steht“. Dies sei nicht nur auf die allgemeine Marienfrömmigkeit zurückzuführen, sondern ebenso auf Basels Status als Marienstadt: „Das Basler Münster war eine Marienkirche, die Gottesmutter Patronin der Stadt“ (ebd.). Auch die Basler Kartause sei seit den 1470er Jahren verstärkt durch marianische Frömmigkeit geprägt worden (vgl. ebd.). Dies gilt insbesondere auch für den Kreis um Johannes Heynlin von Stein, dem Sebastian Brant angehörte. Vgl. Knape, S. 315. Siehe außerdem die Ausführungen weiter oben, Abschnitt 2, S. $229 \mathrm{f}$.

50 Deutschsprachige Rosenkranzliteratur wird in mehreren Basler Offizinen gedruckt, so bei Martin Flach und Bernhard Richel. Vgl. Günthart, S. 28f. Siehe zur Verehrung des Rosenkranzes auch ebd., S. 131.

51 Vgl. Henkel, S. 175; Heinz: Rosenkranz (III. Historisch), Sp. 1304. Siehe außerdem die umfangreiche Studie Klinkhammers (Adolf von Essen) zur Entstehung und Entwicklung des Rosenkranz-Gebetes. 
Konversen der ,Marienpsalter“ des Alanus de Rupe, das Rosenkranz-Bruderschaftsbuch Jakob Sprengers und der zweibändige Folio-Druck Beschlossen gart des Rosenkrantz Marie zur Verfügung. ${ }^{52}$ Sebastian Brant hat eine eigene Rosenkranz-Dichtung verfasst. Sein aus fünfzig sapphischen Strophen bestehendes, auch in die Volkssprache übertragenes Rosarium erschien 1494 in einer Sammelausgabe seiner religiösen Dichtungen - den Carmina in laudem Beatae Mariae virginis multorumque sanctorum - und 1498 erneut in den Varia Carmina. ${ }^{53}$ Das Titelblatt dieser erweiterten Gedichtsammlung zeigt den Autor vor einem Rosenkranz kniend. ${ }^{54}$

\section{Das Crinale B.M.V. Konrads von Haimburg}

Sicherlich ist Worstbrock zuzustimmen, wenn er in seinem Verfasserlexikon-Artikel zu Konrad von Haimburg darauf hinweist, dass das Crinale B. M. V. keineswegs mit dem Gebetstypus des ,Rosenkranzes‘ in Verbindung stehe. Deshalb sei der im fünfzehnten Jahrhundert eindringende Titel Rosarium für dieses am weitesten verbreitete Lied Konrads problematisch, ${ }^{55}$ könne er doch „terminologisch irreleiten“. ${ }^{56}$ Für zeitgenössische Rezipienten dürfte es allerdings ausgesprochen naheliegend gewesen sein, die 50strophige Mariengruß-Dichtung aufgrund ihrer hypertrophen Preisung der himmlisch verklärten Gottesmutter formal wie semantisch in Bezug zum ,glorreichen Rosenkranz ${ }^{6}$ zu setzen. ${ }^{57}$ Denn dieser schließt

52 Vgl. Honemann, S. 255.

53 Vgl. Henkel, S. 175. Neben Brants Fassung des Rosarium in 50 Strophen existiert eine vermutlich durch einen Anonymus erweiterte 63strophige Version. Vgl. ebd., S. 176-181. Siehe zu Brants deutscher Übertragung, die im 1518 publizierten Andachtsbuch Der ewigen wiszheit betbüchlin (VD 16: S 6101) enthalten ist (fol. XCII -XCVI) ), Knape, S. 330-333. Brants Rosen krantz mit blümen des lebens vnd lydens vnsers herren iesu christi orientiert sich am ,schmerzhaften Rosenkranz' (so auch Knape, S. 323) und entspricht damit dem Gesamtprofil des Betbüchlin, welches seine Rezipienten durch eine konsequente Ausrichtung auf die Heilszuträglichkeit der Passion Christi in eine Lebenshaltung des (Mit-)Leidens einüben will.

54 Darauf weist Günthart, S. 131, Anm. 65, hin.

55 Das Crinale ist in über vierzig handschriftlichen Textzeugen erhalten. Vgl. Worstbrock, Sp. 186. Der Titel Rosarium für den Ave-Fünfziger, d.h. den dritten Teil eines vollständigen Marienpsalters, war bereits im dreizehnten Jahrhundert aufgekommen. Vgl. Heinz: Rosenkranz (III. Historisch), Sp. 1304.

56 Worstbrock, Sp. 186.

57 Siehe zur Einteilung des Marienpsalters in einen ,freudenreichen', einen ,schmerzhaften und einen ,glorreichen‘ Rosenkranz, die jeweils fünfzig Ave Maria umfassen, Heinz: Rosenkranz (III. Historisch), Sp. 1303. 
in die Verherrlichung Christi auch die Erhöhung der Gottesmutter ein. ${ }^{58}$ Zudem erinnert das Crinale durch die Verwendung von fünf Strophenanaphern, die jeweils zehn aufeinanderfolgende Strophen einleiten, ${ }^{59}$ an die Unterteilung des AveFünfzigers in Zehnergruppen. ${ }^{60}$ Sowohl Sebastian Brants handschriftliche Crinale-Adaptation als auch die zum Druck gelangte Fassung machen diesen wahrgenommenen Zusammenhang durch ihren jeweiligen Titel - Sant Bernharts rosen krentzelin bzw. Sant Bernarts Rosenkrantz - explizit. In diesem Zusammenhang sei erwähnt, dass Moser Brants Autograph am Blattrand mit einer rudimentären Strophenzählung versehen hat, die mit jeder Zehnerreihe neu einsetzt. ${ }^{61}$ Schließlich verweist auch das Grundmotiv der Mariengruß-Dichtung, das Flechten eines Kranzes aus geistlichen Rosen zur Ehre der Gottesmutter, auf das Beten des Rosenkranzes. Denn der Popularisierung dieser Frömmigkeitsform dienten unter anderem Legenden, welche den Transfer von der materiellen zur spirituellen Ausschmückung Marias narrativ ausgestalten. ${ }^{62}$ Indem die Druckfassung im Anhang des Guldin Spiegel die von den Rezipienten performativ mitzuvollziehende Tätigkeit des ,Ich` als Verfertigung eines Rosenkranzes bezeichnet, spielt sie auf diesen Zusammenhang an: Eyn rosenkrantz ich dir flicht / Nit von blüst der meyen blümen / Sunder von geistlichen rümen / Zierlich dir zu lob gedicht (1,3-6).

Konrads lateinische Dichtung folgt einem fünfzeiligen Strophenschema aus Vierreim plus Waise (aaab). Jeweils zwei Strophen sind durch Reim der

58 Vgl. etwa Clausula 48 im dritten Teil des Marienpsalters, der in einer Kölner Handschrift des späten fünfzehnten Jahrhunderts (Hist. Archiv der Stadt, Best. 7002 [GB 2${ }^{\circ}$ 47) überliefert ist. Bei den Clausulae handelt es sich um Betrachtungen des Lebens Jesu, die relativisch an den Namen ,Jesus‘ im Ave Maria anschließen. Vgl. Heinz: Rosenkranz (III. Historisch), Sp. 1304. Der Anfang von Clausula 48 lautet (fol. 65" zitiert nach Klinkhammer: Adolf von Essen, S. 237): Der dich, hoch-/-gelopte jungfraue, sine irwirdige liebe muter, dor nach holete und off zu sich nam, als wir billichen glouben sullen, mit libe und mit sele und furte dich und erhoete dich boben alle chore der heiligen engele und satzte dich zu siner rechter hant off den koniglichen thron, der dir bereytet was von anbegynne der werlte und kronete dich mit der kronen ewiger eren in gloria.

59 Es handelt sich neben den Grußwörtern Ave, Salve, Gaude, Vale um die Apostrophe O Maria. 60 Diese - bis heute übliche - Gliederung in Zehnergruppen durch ein dazwischentretendes Paternoster ist erstmals klar bei dem Kartäuser Heinrich von Kalkar († 1408) bezeugt. Vgl. Heinz: Rosenkranz (I. Begriff), Sp. 1302; ders.: Rosenkranz (III. Historisch), Sp. 1304.

61 Vgl. Basel, UB, Cod. A IX 27, fol. 195" $196^{\mathrm{v}}-197^{\mathrm{v}}, 198^{\mathrm{v}}$.

62 Vgl. z. B. das erste Exempel aus der ,Zwanzig-Exempel'-Schrift, die vermutlich von Dominikus von Preußen aus hinterlassenen Papieren Adolfs von Essen zusammengestellt und zu Propagandazwecken verschickt wurde. Der kurze Text handelt von einem Laienbruder, der auf Anraten eines geistlichen Mentors die Herstellung von ,echten` Blütenkränzen für eine Marienstatue durch das tägliche Beten des Ave-Fünfzigers - und damit durch einen geistlichen rosenkrantz - ersetzt und dafür belohnt wird. Vgl. Klinkhammer: Adolf von Essen, S. 172-174 (zum ,geistlichen Rosenkranz': S. 174, Z. 38). 
Schlussverse zu einer Doppelstrophe zusammengeschlossen. Da dieser formale Zusammenhang weder von Brants handschriftlicher Crinale-Adaptation noch von der gedruckten Fassung übernommen wird, werden die Strophen im Folgenden einfach gezählt. ${ }^{63}$ Inhaltlich ergehen sich die 250 Verse des Mariengrußes - so Worstbrock - „in einem Rausch von preisenden Attributen und Sinnbildern“. 64 Diese rufen zwar das etablierte Inventar spätmittelalterlicher Marienfrömmigkeit auf, dies jedoch in einer ausgesprochen kunstvollen, die Vorstellungskraft und den Intellekt der Rezipienten gleichermaßen stimulierenden Weise. Wenige Hinweise hierzu müssen an dieser Stelle genügen.

Die erste Strophe, die das geistliche Kranzflechten als Grundmotiv der Dichtung einführt, beginnt mit einem Vierfachgruß an Maria: Ave, salve, gaude, vale. Im Anschluss an diese akkumulierte Grußformel wendet sich das ,Ich mit der Apostrophe $O$ Maria namentlich an die Gottesmutter $(1,2)$. Auf diese Weise ist die durch die Strophenanaphern bestimmte Struktur des Crinale ebenso raffiniert wie zwanglos in den Liedbeginn eingewoben.

Wie die inhaltliche Gestaltung der ersten Strophe bereits ankündigt, wird die auf stetige Selbstüberbietung ausgerichtete Metaphorik der Mariendichtung von vegetativer Bildlichkeit dominiert. So weist Worstbrock darauf hin, dass jedes der vier Grußwörter von einer neuen Blumenmetapher begleitet wird: rosa $(1,3 ; 3,1)$, campi flos $(11,1)$, lilium $(21,5)$ und viola $(31,5) .{ }^{65}$ Auch die Anrede $O$ Maria in den letzten zehn Strophen ist flankiert „von einer Fülle von Pflanzen aus der Tradition mariologischer Bildlichkeit“. ${ }^{66}$ Häufig verbindet sich mit der vegetativen Metaphorik der Aspekt der Fruchtbarkeit: So erscheint Maria als Rose, die aus dem Stamm eines königlichen Geschlechts hervorbricht (3,1f.), um ihrerseits eine Blüte oder Frucht - nämlich Christus - zu tragen (vgl. 14,1f.; 32,1-5; 34,1-5).

Weitere Bildbereiche ergänzen die Pflanzenmetaphorik: In unterschiedlicher Weise wird Maria als Gefäß oder Gemach vorgestellt, welches Gott bzw. den Sohn Gottes in sich birgt (vgl. 4,3-5; 22,1-5; 24,3-5; 27,5; 33,1f.; 36,1-5). Mit dieser Gefäßmetaphorik verbindet sich die Vorstellung von Maria als Überströmende, Gaben Verteilende, Nahrung und Heilung Spendende (vgl. 8,1-5; 18,3-5; 28,3-5). Einem in der marianischen Lyrik äußerst beliebten, mehrfach titelgebenden Motiv entspricht die Repräsentation Marias als Meerstern (stella maris; vgl. 9,1). ${ }^{67}$ Die

63 Also Strophe 1, 2, 3, 4 usw. statt 1a, 1b, 2a, 2b.

64 Worstbrock, Sp. 186.

65 Vgl. ebd., Sp. 186.

66 Vgl. ebd., Sp. 186. Insbesondere sind hier die von vegetativen Metaphern geradezu überbordenden Strophen 41 und $42 \mathrm{zu}$ nennen.

67 Vgl. den Hymnus Ave maris stella (AH 51, S. 140-142, Nr. 123) und die Sequenz Ave praeclara maris stella (AH 50, S. 313-315, Nr. 241). Beide wurden vielfach - die Sequenz auch von Sebastian 
hier implizierte Lichtmetaphorik wird verschiedentlich wieder aufgegriffen (vgl. 12,1-5; 27,1-3; 30,4f.; 31,2f.); vorherrschend ist sie in Strophe 23, die Maria als von Gott eingesetzte Fackel feiert, welche den Menschen zum göttlichen Licht zurückführt. ${ }^{68}$ Ebenfalls präsent ist der Topos der ,Süßigkeit' Mariens, der sein sinnliches Potenzial vor allem im Bild des Honigs bzw. der Honigwabe entfaltet (vgl. 11,4f.; 44,1). ${ }^{69}$ Die Schutzfunktion der Gottesmutter wird in einer Metaphorik der Wehrhaftigkeit - Maria erscheint als die Feinde zurückschlagender Schild (20,2f.) und als uneinnehmbarer Turm (46,1-5) - zum Ausdruck gebracht.

Die Kopplung der verschiedenen Bildbereiche erfolgt assoziativ. Ihre variierende Wiederholung in immer neuen katachrestischen Kombinationen regt die Vorstellungskraft des Rezipienten an, ${ }^{70}$ ohne dass Maria jemals klar umrissene Konturen gewinnt. In all ihrer Menschzuwendung bleibt sie eine entrückte, nur in meditativen Annäherungen erfassbare Figur. Diese in ihrer poetischen Gestaltung angelegte Grundaussage der Mariengruß-Dichtung findet in Strophe 19 expliziten Ausdruck: Salve, cui dulce fari, / De qua pium meditari (19,1f.). Worstbrocks Hinweis, dass Konrads Lieder ,sicherlich für die private Andacht ihrer Leser bestimmt waren“, ${ }^{71}$ findet so eine zusätzliche Bestätigung in der Gesamtkomposition des Crinale. Es ist als marianisches ,Meditationslied“ konzipiert, dessen Bilderfülle zur imaginativen Versenkung anreizt. Damit aber gewinnt die Hinwendung zur jenseitigen advocatrix eine Intensität, die deren Heilshandeln für den Meditierenden potenziert.

Die den gewählten Metaphern gemeinsame Verankerung in der spätmittelalterlichen Marienfrömmigkeit garantiert, dass sie ungeachtet ihrer Zugehörigkeit zu unterschiedlichen Bedeutungsfeldern miteinander korrespondieren. Dies befähigt den Rezipienten dazu, verschiedene Bezüge zwischen den Strophen her-

Brant - in die deutsche Sprache übertragen. Siehe dazu die Datenbank des ,Berliner Repertoriums': http://opus.ub.hu-berlin.de/repertorium/id/6860 (Ave maris stella, ID: 6860; 14. September 2019); http://opus.ub.hu-berlin.de/repertorium/id/6261 (Ave praeclara maris stella, ID: 6261; 14. September 2019). Vgl. zu Ave praeclara maris stella ferner die umfangreiche Studie von Rothenberger sowie Kraß: ,Ich gruess dich gerne‘. Siehe zu Brants Adaptation von Ave praeclara maris stella Knape, S. 325-327; Kraß: ,Ich gruess dich gerne‘, S. 311f. Siehe zum Hymnus und zur Sequenz ferner Kraß: ,Ave maris stella'.

68 Der Text lautet: Gaude lampas, quam exstruxit / Deus orbi, quae dum luxit, / Nova nobis tunc illuxit, / Quae ad lucem nos reduxit / Lux inexstinguibilis.

69 Vgl. zur ,Süßigkeit‘ Mariens ferner 19,1-3; 21,1f.; 41,1.

70 Als Beispiel sei Strophe 35 angeführt, welche den Bildbereich des Lichts mit dem Topos der geistlichen ,Süßigkeit‘ verschränkt: Das ,Ich` ruft hier Maria als glänzende Morgenröte der wahren Sonne an, die den Gläubigen den Balsam der Süßigkeit einträufeln solle.

71 Worstbrock, Sp. 182. 
zustellen und abhängig von seinem Wissenshorizont weitere Sinnebenen des Crinale zu generieren.

Einen formalen Hinweis auf mögliche semantische Verschränkungen bietet der Zusammenschluss von jeweils zwei Strophen zu einer Doppelstrophe. Als Beispiel seien die Strophenpaare 33 und 34 sowie 37 und 38 genannt. Im ersten Fall grüßt das ,Ich` Maria zunächst als Gefäß des wahren Himmelsbrotes (33), im folgenden Versikel dann als Weinrebe, welche die den Menschen erquickende Traube trägt (34). Die Erkenntnis des impliziten eucharistischen Bezuges, der das Strophenpaar zusammenbindet, obliegt dem jeweiligen Rezipienten. Im zweiten Fall identifiziert das anrufende ,Ich“ Maria mit verschiedenen alttestamentarischen Frauenfiguren. Während der erste Versikel (37) Abigail und Ruth als placatrix und oratrix ins Zentrum stellt, erfolgt im korrespondierenden Versikel (38) eine Gleichsetzung mit Judith und Hester als Beschützerinnen vor feindlichen Attacken. In der Zusammenschau verweisen die vier Frauenfiguren auf die grundlegenden Funktionen der Gottesmutter für den Menschen: die Besänftigung Gottes und die Abwehr des Teufels. Die Entschlüsselung der biblischen Hintergründe und ihre Übertragung auf Maria muss erneut der Rezipient leisten.

Durch das variierende Aufrufen der gleichen Bildbereiche entstehen zudem weitere strophenübergreifende Zusammenhänge, die zu theologischen Ausdeutungen einladen. So heißt es in Strophe 9, dass aus Maria als hellem Meerstern das Sonnenlicht hervorbreche: Ave clara stella maris, / Qua processit lux solaris (9,1f.). In Strophe 12 dagegen wird Maria als farbig glänzender Regenbogen von der göttlichen Sonne erleuchtet. ${ }^{72}$ Die Lichtmetaphern greifen dergestalt ineinander, dass Marias Rolle als Hervorbringerin des Sonnenlichtes an ihre Überstrahlung durch die göttliche Sonne zurückgebunden wird. Darüber hinaus signifiziert die semantische Doppelung der Sonne - als auf Maria Einwirkende und aus ihr Heraustretende - die Wesenseinheit von Vater und Sohn. Brants volkssprachliche Adaptation lässt diesen Zusammenhang durch eine identische Begrifflichkeit in beiden Strophen noch deutlicher hervortreten. ${ }^{73}$ Die Eingangsverse der Strophe 9 lauten in Brants Übertragung: Aue lyehter stern des meres / Vsz dem spryszt die sunn der eren. ${ }^{74}$ In Strophe 12,4 schließt sich als Aussage über den Regenbogen an: Dån erglest die Sunn der eren. ${ }^{75}$

72 Der Text lautet: Salve arcus aerinus, / Colorosus non supinus, / Clare lucens, vespertinus / Quem illustrat sol divinus, / Stans in signum foederis.

73 Gleiches gilt für die Druckfassung, die sich hier Brants Version anschließt. Vgl. Spiegel (Anhang), fol. $36^{\mathrm{r}-\mathrm{v}}$.

74 Basel, UB, Cod. A IX 27, fol. $196^{\mathrm{r}}$.

75 Basel, UB, Cod. A IX 27, fol. 196. 
Abgesehen von den gängigen alttestamentarischen Präfigurationen Marias dem brennenden Dornbusch (vgl. 6,2f.), dem benetzten Fell Gideons (vgl. 25,1-5) oder dem grünenden Stab des Aaron (vgl. 32,1-5) - integriert das Crinale schwieriger durchschaubare typologische Bezüge, die allein bibelkundigen Rezipienten aufgefallen sein dürften. Als Beispiel sei Strophe 13 angeführt, in der Maria als wegweisende ,Feuersäule، (13,1: columna ignis) und wunderkräftige ,Wolke' (13,2: nubes miris signis) tituliert wird. Die biblische Folie für diese Metaphern ist der Auszug der Israeliten aus Ägypten, den Jahwe tagsüber in Gestalt einer Wolken- und nachts in Gestalt einer Feuersäule begleitet (vgl. Ex 13,21f.). Die Strophe rührt insofern an die Grenzen der Orthodoxie, als sie alttestamentarische Erscheinungsformen Gottes auf Maria hin auslegt.

Durchzogen ist das Crinale von einer dreifach gestaffelten räumlichen Struktur: An unterster Position, in exsilio $(18,5)$, befindet sich der Mensch. Ihm unerreichbar bleibt die transzendente Erhabenheit Gottes, der die oberste Stelle innerhalb der Raumkomposition einnimmt. Zwar ist die Menschwerdung Christi aufgrund der Mutterschaft Mariens durchgängig präsent; zudem konstatiert Strophe 44, dass Christus durch Maria zum Bruder des Menschen geworden sei: Qui per te est nobis frater (44,4). Der unmittelbaren Adressierung durch die Gläubigen entzieht sich der Gott des Crinale jedoch, da seine Aufmerksamkeit ausschließlich Maria gilt. Nur sie ist Dei placens oculis $(2,5)$ und darf sich seiner Gegenwart erfreuen (vgl. 30,1f.). Die Gottesbegegnung des Menschen bleibt auf die Beurteilung durch den strengen Richtergott reduziert, der durch Maria besänftigt werden muss, um den Sünder letztlich in sein Reich aufzunehmen (vgl. 45,1-5; 50,1-5).

Die Rolle Marias als Vermittlerin zwischen Gott und Menschen ist im Crinale daher absolut: Weder tritt ihr ein gütiger Christus zur Seite, der als zusätzliche Anrufungsinstanz des Gläubigen infrage käme, noch existiert eine direkte Zuwendung Gottes zum Menschen. Vielmehr bleibt es ausschließlich der Gottesmutter überlassen, die Gläubigen zum Heil zu führen ${ }^{76}$ und ihnen die göttlichen Gnadengaben mitzuteilen: Nectar praebe supernorum lautet dementsprechend eine der Bitten des anrufenden ,Ich $(8,4) .{ }^{77}$ Diese Konzentration aller Heilskompetenz auf Maria korrespondiert mit der Anlage des Gedichtes als Mariengruß.

Ihrer Aufgabe als Interzessorin entsprechend nimmt Maria innerhalb der Raumstruktur des Crinale die mittlere Position ein. Verortet ist diese im Zwi-

76 In Strophe 47 wird diese Funktion in das Motiv der Himmelsleiter gekleidet, die Unterstes (imus) und Oberstes (supernus) miteinander verbindet. Vgl. zu Marias Rolle als den Heilsweg Weisende auch die Ausführungen weiter oben, S. 235, zur Lichtmetaphorik.

77 Vgl. auch 18,3-5: Dona regis pretiosa / Impertire gratiosa / Nobis in exsilio. Siehe zu Marias Rolle als Gnadenvermittlerin ferner die Ausführungen weiter oben, S. 234, zur Gefäßmetaphorik. 
schenbereich von Transzendenz und Immanenz, allerdings mit einer deutlichen Akzentuierung der Jenseitigkeit Marias. Zwar verweist das ,Ich“ in seinen Anrufungen wiederholt auf Marias Mutterschaft und damit auf ihre heilsgeschichtliche Funktion. ${ }^{78}$ Sein Gruß richtet sich jedoch an die aller irdischen Schmerzen enthobene, in die himmlische Glorie entrückte Himmelskönigin. ${ }^{79}$ Im sprachlichen wie visuellen Reichtum ihrer Lobpreisungen spiegelt sich die Fülle ihrer in der Gottesmutterschaft fundierten Rettungsmacht, die der jeweilige Rezipient im performativen Mitvollzug des geistlichen ,Rosenkranzflechtens' für sein eigenes Seelenheil aktiviert.

\section{Sebastian Brants Übertragung des Crinale (Sant Bernharts rosen krentzelin)}

\subsection{Die Basler Handschrift A IX 27}

Brants Autograph befindet sich in einer für die Überlieferung von Moser-Texten zentralen Sammelhandschrift: ${ }^{80}$ Basel, UB, Cod. A IX 27 (fol. $195^{\mathrm{r}}-202^{\mathrm{v}}$ ). Es handelt sich um eine sehr eng gebundene, 334 Blätter umfassende Papierhandschrift des ausgehenden fünfzehnten Jahrhunderts, ${ }^{81}$ die zahlreiche Einträge von der Hand Ludwig Mosers, aber auch des Konventualen Martin Streulin sowie anderer namentlich nicht bekannter Schreiber enthält. ${ }^{82}$ Zudem ist ein Druck eingebunden (fol. $294^{\mathrm{r}}-313^{\mathrm{v}}$ ). Die Handschrift beinhaltet sowohl lateinische als auch volkssprachliche Texte.

Auffallend ist der auf der Innenseite des Vorderdeckels und auf fol. $1^{\mathrm{r}}$ dokumentierte Wechsel der alten, aus der Basler Kartause stammenden Signaturen. Ihr Austausch lässt darauf schließen, dass die Handschrift aus dem Bestand der

78 Vgl. z. B. die Strophen 5 sowie 15-17. In poetischer Überhöhung sind Marias Schwangerschaft und die Geburt ihres Sohnes zudem in der vegetativen Bildlichkeit und der Gefäßmetaphorik des Crinale präsent. Vgl. oben, S. 234.

79 Auf die semantische Nähe des Crinale zum ,glorreichen Rosenkranz‘ wurde bereits hingewiesen.

80 Vgl. Günthart, S. $101 \mathrm{f}$.

81 Aufgrund der engen Bindung des Codex, die ein beschädigungsfreies Aufschlagen nur bis zu einem bestimmten Grad gestattet, lässt sich die Anzahl der einzelnen Lagen nicht ermitteln. Zudem ist eine Digitalisierung der Handschrift nach Auskunft der Bibliothek nicht möglich.

82 Vgl. die ausführlichen Handschriftenbeschreibungen von Binz, S. 133-139, und Honemann, S. 198-202. Siehe ferner die Kurzbeschreibungen Haellers, S. 30, und Scarpatettis, S. 79f. Zur Identifizierung der Hand Martin Streulins vgl. Scarpatetti, S. 80; Honemann, S. 198. 
Mönchsbibliothek in die Laienbibliothek übergegangen ist. Auf fol. $1^{\mathrm{r}}$ ist der Codex zunächst mit einer E-Signatur versehen, die den Erbauungsschriften der Konventualenbibliothek zugeordnet war. ${ }^{83}$ Die ältere Signatur E 110, die auf eine ursprüngliche Zugehörigkeit zur sogenannten bibliotheca nova schließen lässt, ${ }^{84}$ ist durchgestrichen und durch die Kennzeichnung E clvij ersetzt. Diese Kombination aus Großbuchstabe und römischer Zahl deutet auf eine Wanderung der Handschrift in die zweite Abteilung der Mönchsbibliothek, die bibliotheca vetus bzw. antiqua, hin. ${ }^{85}$ Die jüngste und daher letztgültige Signatur $-D$ lxxx pro armario vulgari - findet sich auf der Innenseite des Vorderdeckels und signalisiert die Aufnahme in die Laienbibliothek. ${ }^{86}$

Diese Zuordnungsschwierigkeiten mögen durch die Zweisprachigkeit der Handschrift verursacht worden sein. Deren anfängliche Einordnung in die Mönchsbibliothek bestätigt, dass die Konventualen deutschen Texten keineswegs ablehnend gegenüberstanden. ${ }^{87}$ Zwar stellte Ludwig Moser als überaus aktiver Betreuer volkssprachlicher Publikationen eine Ausnahme unter den Basler Klerikern dar, ${ }^{88}$ seine Tätigkeit als Übersetzer fand innerhalb der Kartause jedoch große Anerkennung. Dementsprechend konzentriert sich der titulus des Codex (fol. $1^{\text {r) }}$ ganz auf sein Schaffen. ${ }^{89}$ Die Handschrift enthalte - so wird ausgeführt varia pulchraque opuscula, die durch den andächtigen Vater und Mitbruder Ludwig Moser kunstgerecht in die Volkssprache übertragen worden seien (in linguam nostram vernaculam concinne interpretata). Genauer handele es sich um den zweiten Teil seiner Übersetzungen. Im Anschluss werden die dazugehörigen Werke als ,Hauptinhalte، der Handschrift (principaliora hic contenta) nummeriert aufgelistet. Innerhalb dieser Aufzählung befindet sich als Nr. 7 allerdings auch

83 Vgl. Honemann, S. 15; Burckhardt: Bibliotheksaufbau, S. 38.

84 Der zugleich als Bibliothekar amtierende Prior Jakob Louber (vgl. oben, Abschnitt 2, S. 229) unterteilte die Mönchsbibliothek in eine ,alte‘ und eine ,neue‘ Bibliothek. Die Signaturen der Letzteren bestehen aus einem Großbuchstaben mit nachfolgender arabischer Zahl. Vgl. Honemann, S. $14 \mathrm{f}$.

85 Siehe zu den Signaturen der ,alten` Bibliothek (vgl. die vorhergehende Anmerkung) Honemann, S. 15.

86 Vgl. Honemann, S. 199. Der Buchstabe $D$ steht im Fall der Laienbibliothek nicht für eine inhaltliche Zuordnung, sondern für ein bestimmtes Format: $D$ entspricht der forma regularis (Oktav). Vgl. Honemann, S. 27.

87 Sexauer, S. 123, spricht von einer „beschränkte[n] Gleichberechtigung des Deutschen“, die in der Kartause allmählich zum Tragen komme. Siehe ferner ebd., S. 159. Auch Honemann, S. 20, erwähnt die „deutschen Bücher der Mönchsbibliotheken“. Siehe außerdem ebd., S. 263-268 (,Literatur für Laienbrüder und Mönche').

88 Vgl. Günthart, S. 21.

89 Siehe zum genauen Wortlaut des titulus Binz, S. 133; Honemann, S. 199. 
das Crinale Sancti Bernardi a S. Brant compositum. ${ }^{90}$ Bereits in dieser Subsumption der Brantschen Adaptation unter Mosers Schaffen kündigt sich die Verdrängung von Brants Autorschaft an. Noch ist diese jedoch präsent und wird durch Brant selbst abgesichert - dies nicht nur durch die Eigenhändigkeit seines Eintrages, sondern zusätzlich durch sein Monogramm $(S b)$ neben dem abschließenden Amen (fol. 202 ${ }^{v}$ ) des Mariengrußes. ${ }^{91}$

Der dergestalt fixierte Anspruch Brants auf die Anerkennung von Sant Bernharts rosen krentzelin als sein geistiges Eigentum bleibt innerhalb der Handschrift jedoch prekär. Denn bei dieser handelt es sich trotz ihrer Wertschätzung innerhalb der Kartause ${ }^{92}$ keineswegs um eine repräsentative oder auf ,Endgültigkeit‘ ausgerichtete Textsammlung. Vielmehr befindet sich Brants Adaptation in einem ,Umfeld der Vorläufigkeit‘. Der Codex ist insgesamt „schnell und unsorgfältig geschrieben“. ${ }^{93}$ Zumindest hinsichtlich seiner volkssprachlichen Inhalte scheint er als eine Art ,Werkstattexemplar' fungiert zu haben, in dem Texte für die Drucklegung in Amerbachs Offizin zusammengestellt und bearbeitet wurden. ${ }^{94}$ Honemann weist auf die „Spuren von Druckerschwärze und andere Merkmale“ hin, die erkennen lassen, dass die in Cod. A IX 27 enthaltenen ersten beiden Teile des Guldin Spiegel des Sunders sowie die in den Anhang dieser Publikation aufgenommene Vszlegung des Gloria patri als Druckvorlage dienten. ${ }^{95}$

90 Weder Binz noch Honemann geben die Nummerierung der Handschrift wieder. Honemann führt stattdessen in Klammern die jeweilige Nummer im Moser-Werkverzeichnis der Basler Kartause (vgl. die Edition ebd., S. 145-149) an.

91 Offen bleibt die Motivation Brants für die Abfassung der Crinale-Übertragung. Es könnte sich ebenso um eine Auftragsarbeit wie um eine Freundesgabe handeln.Vgl. Knape, S. 315. Keineswegs ungewöhnlich ist die Überlieferung von Brants Adaptation in einer Handschrift der Basler Kartause. Knape stellt fest, dass „fast alle Handschriften mit Brant-Liedern aus der Zeit zwischen 1490 und 1525 [...] zum Basler Kartäuserkloster“ gehören. Vgl. ebd.

92 Aufgrund dieser Wertschätzung hat die Handschrift Eingang in den Katalog der Basler Kartause gefunden. In dieses vom Bibliothekar Urban Moser zu Beginn des sechzehnten Jahrhunderts angelegte Verzeichnis hat sein Nachfolger Georg Carpentarius auch die principaliores et nominatiores unter den volkssprachlichen Büchern aufgenommen. Vgl. Honemann, S. 16. Im Katalog finden allerdings nicht alle Texte der Handschrift Erwähnung, sondern (abgesehen vom eingebundenen Druck) nur die Schriften Ludwig Mosers. Vgl. ebd., S. 198. Siehe auch unten, Abschnitt 5.4, S. 257-259.

93 Günthart, S. 102. Dies gilt jedoch nicht für Brants Autograph. Er hat den Text seiner CrinaleAdaptation in Reinschrift eingetragen. Die Verse sind abgesetzt, die Strophenanfänge durch ausladende Eingangsbuchstaben als solche markiert.

94 Zudem scheint der Codex zur Abschrift ausgeliehen worden zu sein. Vgl. Mosers Bemerkung auf fol. 222v (siehe Binz, S. 137).

95 Vgl. Honemann, S. 199f. Schwarze Fingerabdrücke und Schmierflecken ziehen sich allerdings durch die gesamte Handschrift. Sie befinden sich auch neben Brants Autograph, welches in der 
Bei den von Honemann erwähnten ,anderen Merkmalen' dürfte es sich um die Markierungen für Seitenumbrüche handeln, die eine unbekannte Hand in die Handschrift eingetragen hat. ${ }^{96}$

Allerdings sind weder alle Moser-Übersetzungen des Codex gedruckt worden ${ }^{97}$ noch beinhaltet er umgekehrt alle Moser-Texte, die Aufnahme in den Guldin Spiegel des Sunders fanden. ${ }^{98}$ Zudem wurden in den ersten beiden Teilen des gedruckten Spiegel Elemente ergänzt, die in der Handschrift fehlen. ${ }^{99}$ Mehrfach lässt Cod. A IX 27 ein intensives Ringen um die ,richtige‘ Gestaltung des Drucks erkennen. So sind der Titel und die Vorrede des Guldin Spiegel in der Handschrift kreuz und quer durchgestrichen. ${ }^{100}$ Die eliminierte Vorrede scheint jedoch anregend auf das Inhaltsverzeichnis des Drucks gewirkt zu haben. ${ }^{101}$

Besonders deutlich tritt der konzeptionelle Charakter der Handschrift nach dem Abschluss des zweiten Spiegel-Teils (fol. 148v) hervor. ${ }^{102}$ Die hier folgende Überschrift Eyn kurtze form teglicher bicht geistlicher personen ist durchgestrichen. Stattdessen wurde mit blasserer Tinte folgender Vermerk hinzugefügt: Nachdem sol doctoris de lapide buchlin ston ${ }^{103}$ und nutz von dem gloria patri vnd das selb wirt das tritt teyl. Auf fol. $149^{\mathrm{r}}$ wurde mit dem Eintrag dieses vorgesehenen dritten Teils begonnen (Das dritt vnd lest teil dis buchlins sollen wir gott zu lob anheben in danckbarkeit siner gnaden). Der Text bricht jedoch auf derselben Seite ab. Eine kurze lateinische Bemerkung - non fiat istud - weist auf seine Verwerfung für den

hier vorliegenden sprachlichen Gestalt keinen Eingang in den Druck fand.Vgl. z. B. fol. $197^{\mathrm{r}-\mathrm{v}}, 198^{\mathrm{r}}$, $200^{\mathrm{r}}$. Jedenfalls belegen die Rückstände von Druckerschwärze eindeutig, dass ein Setzer den Codex in die Hand genommen hat. Gleiches gilt - so Sexauer (S. 107) - für ,viele Bände aus der alten Kartausenbücherei“".

96 Vgl. Günthart, S. 102.

$97 \mathrm{Zu}$ den ungedruckten Texten gehört z.B. eine Gerson-Übersetzung. Vgl. Binz, S. 135 (Nr. 14); Honemann, S. 200. Umfangreiche Exzerpte der ungedruckten Texte bietet Haeller, S. 30-55.

98 Nicht in der Handschrift enthalten sind z. B. die Teile 3 und 4 des gedruckten Spiegel. Zu Teil 3 siehe die folgenden Ausführungen sowie Anm. 104. Bei Teil 4 handelt es sich um eine Übertragung des Hortulus rosarum (in valle lacrimarum) von Thomas von Kempen.

99 Dies gilt z.B. für die Widmungsvorrede (Guldin Spiegel, fol. $2^{\mathrm{r}}-3^{\mathrm{v}}$ ), das Inhaltsverzeichnis (ebd., fol. $4^{\mathrm{r}-\mathrm{v}}$ ) und die nutzliche vorrede zum ersten Teil (ebd., fol. $4^{\mathrm{v}}-5^{\mathrm{r}}$ ). Erst ab fol. $5^{\mathrm{v}}\left[=\mathrm{a}^{5} \mathrm{~b}\right]$ folgt der Wortlaut des Drucks der Handschrift (dort fol. 36'). Vgl. auch Günthart, S. 102.

$100 \mathrm{Vgl}$. fol. $35^{\mathrm{r}-\mathrm{v}}$ sowie die ersten beiden Zeilen auf fol. $36^{\mathrm{r}}$.

101 Das Incipit der durchgestrichenen Vorrede (fol. $35^{\mathrm{r}}$ ) lautet: Der guldin Spiegel des suinders / lert sund myden vnd / zeigt den weg zu dem ewigem leben. Ähnlich lautet der Beginn des Inhaltsverzeichnisses im Druck (fol. $4^{\mathrm{r}}$ ): Disz bůchlyn ist genant der gulden spiegel des sünders / vnd lert den sünder sünd vnd laster myden vnd den weg zu ewiger selikeit.

102 Vgl. zum Folgenden auch Binz, S. 135; Günthart, S. 102.

103 Unklar ist, auf welche Schrift Johannes Heynlins von Stein (zu ihm siehe oben, Abschnitt 2, S. 229f.) sich der Hinweis bezieht. 
Druck hin. ${ }^{104}$ Es folgen mehrere leere Seiten (fol. 149v-154v ), die vermutlich für die Niederschrift des dritten Teils gedacht waren. Überhaupt enthält die Handschrift zahlreiche unbeschriebene Seiten, die möglicherweise Ergänzungen und Nachträge - auch innerhalb bereits ,fertiger` Texte - aufnehmen sollten. ${ }^{105}$

Angesichts der Vorläufigkeit bzw. Unvollständigkeit von Cod. A IX 27 und der skizzierten Differenzen gegenüber der Druckausgabe des Guldin Spiegel des Sunders müssen dessen Setzer auf weitere Vorlagen zurückgegriffen haben. Hier besteht allerdings eine Überlieferungslücke, die auch Brants Adaptation des Crinale B. M. V. betrifft. Denn aufgrund ihrer tiefgreifenden Umformung für die Drucklegung kann die Mariengruß-Dichtung nicht unmittelbar aus Cod. A IX 27 übernommen worden sein. ${ }^{106}$ Das konzeptionelle, auf Überarbeitung und Verbesserung angelegte Profil der Handschrift scheint den in Brants Signatur dokumentierten Anspruch geistiger Urheberschaft überlagert zu haben, sodass eine kreative Aneignung seiner Crinale-Übertragung als legitim wahrgenommen wurde.

\subsection{Poetischer Anspruch und inhaltliches Profil von Brants Übertragung}

Für Sebastian Brants Umgang mit dem lateinischen Prätext ist bereits die erste Strophe seiner Crinale-Übertragung signifikant. Sie sei daher in synoptischer Gegenüberstellung mit Konrads Dichtung zitiert:

Konrad von Haimburg: Crinale B. M. V.

(AH 3, S. 22)

Ave, salve, gaude, vale, O Maria, non vernale, Sed his rosis spiritale Tibi plecto nunc crinale Figurarum flosculis.
Sebastian Brant: Sant Bernharts rosen krentzelin (Basel, UB, Cod. A IX 27, fol. 195')

Aue / Salue / Gaude / Vale

0 maria / vsz dem tale

Der zytlosen ich nit flieht

Jetz ein krentzelin von Rosen

Sunder blůmen gantz on mosen

104 Im gedruckten Guldin Spiegel des Sunders besteht dessen dritter Teil aus zwölf kurzen Erläuterungen zu Sünde, Reue, Sündenvergebung, Beichte und Absolution. Die Vorlage ist bislang unbekannt. Mosers Auslegung des Gloria patri wird nicht - wie offenbar ursprünglich geplant - in den Hauptteil des Spiegel aufgenommen, sondern steht als zweiter Text des Anhangs (siehe oben, Abschnitt 1, S. 223f.) unmittelbar vor der Crinale-Übertragung. Siehe zur Konzeption des gedruckten Spiegel unten, Abschnitt 5.3.

105 So ist die Niederschrift von Mosers Auslegung des Gloria patri (fol. $155^{\mathrm{r}}-164^{\mathrm{r}}$ ), nach Honemann die Druckvorlage für den Spiegel (siehe oben, S. 240f.), mehrfach durch Leerseiten unterbrochen (fol. 155 $159^{\mathrm{v}}, 160^{\mathrm{r}}, 161^{\mathrm{v}}, 162^{\mathrm{r}}$ ).

106 Darauf weist auch Günthart, S. 102, hin. 
Fortsetzung

Konrad von Haimburg: Crinale B. M. $V$.

(AH 3, S. 22)

\author{
Sebastian Brant: Sant Bernharts rosen krentzelin \\ (Basel, UB, Cod. A IX 27, fol. 195') \\ Hab ich geistlich dir gedieht.
}

Zunächst fällt auf, dass Brant den Gedichteingang seiner Vorlage übernimmt und damit signalisiert, dass seine Übertragung in inhaltlicher Hinsicht die Anbindung an den lateinischen Prätext wahren wird. Dies gilt allerdings nicht auf der formalen Ebene. Denn anstatt das fünfzeilige Strophenschema des Crinale zu adaptieren, verwendet Brant ein Sechs-Zeilen-Schema mit Schweifreim (aabccb). ${ }^{107}$ Der Titel der Druckfassung informiert darüber, dass dieses Schema der populären Sequenz Salve mater salvatoris entspricht: ${ }^{108}$

Sant Bernharts Rosenkrantz den er selbs vom heiligen geist gelert der heiligen iungfrowen maria gotts muiter ze lob vsz der heiligen geschrifft gedichtet hat. Den mag man singen noch der noten wyse / als der Sequentz lutet / Salue mater saluatoris. ${ }^{109}$

Es geht Brant also offensichtlich darum, Sangbarkeit herzustellen und damit ein Grundpostulat seines volkssprachlichen Liedschaffens zu erfüllen. ${ }^{110}$ Zudem erfolgt durch die formale Angleichung an die Sequenz Salve mater salvatoris eine Rückbindung der Crinale-Übertragung an die Liturgie. ${ }^{111}$

Brant sieht sich also der Herausforderung ausgesetzt, den Bilderreichtum des lateinischen Mariengrußes und dessen kunstvolles poetisches Arrangement in die Volkssprache zu übertragen, während er zugleich einem seiner Vorlage fremden Formprinzip gerecht werden muss. Vor diesem Hintergrund lässt sich Brants Adaptation der ersten Strophe als Ausdruck seines dichterischen Selbstbewusstseins lesen. Denn obgleich diese das Grundmotiv des geistlichen Kranzflechtens aus ihrer Vorlage übernimmt, verleiht sie dem grüßenden ,Ich` eine eigenmächtigere Position. Im Crinale erklärt der oder die Anrufende, dass er oder

107 Vgl. auch Knape, S. 313, 320. Auf einige wenige Transkriptionsfehler in Knapes Wiedergabe des Textes nach Cod. A IX 27 sei an dieser Stelle hingewiesen: 23,3 (Knape, S. 322: [...] domit man

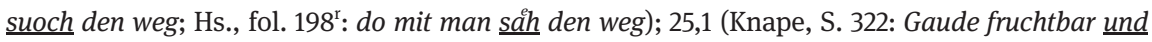
erlühtet; Hs., fol. 198v: Gaude fruichtbar erd erlühtet); 42,6 (Knape, S. 323: cafy und all specery; Hs., fol. $201^{\mathrm{r}}$ : Casy / vnd all specery).

108 Ediert ist diese Sequenz in AH 54, S. 383-386, Nr. 245. Siehe zu ihr auch die Datenbank des ,Berliner Repertoriums‘ (ID: 6854): http://opus.ub.hu-berlin.de/repertorium/id/6854 (19. September 2019).

109 Guldin Spiegel (Anhang), fol. $35^{\mathrm{r}}$.

110 Vgl. Knape, S. 311-314. Siehe zur Sangbarkeit von Brants Übertragung der Sequenz Ave praeclara maris stella auch Rothenberger, S. $289 \mathrm{f}$.

111 Siehe dazu auch weiter unten, Abschnitt 5.5, S. 262 f. 
sie ,jetzt‘ (nunc) keinen echten, sondern einen geistlichen Blütenkranz für die Gottesmutter flechten wolle. In Brants Adaptation dagegen weist das ,Ich' die Bezeichnung ,flechten' für seine kreative Aktivität zurück und ersetzt sie durch das Verb ,dichten' $(1,6)$. Zudem verschiebt sich die zeitliche Perspektive: Das krentzelin von Rosen werde nicht, jetzt' angefertigt, sondern liege als Ergebnis des Schaffensprozesses bereits vor. Prononciert stellt das ,Ich‘ im Schlussvers seine eigene Leistung in den Vordergrund: Hab ich geistlich dir gedieht. Damit aber gewinnt die Anforderung an den Rezipienten ebenfalls eine neue Schattierung. Ist dieser im lateinischen Crinale zum performativen Mitvollzug des geistlichen Kranzflechtens eingeladen, bleibt ihm in Brants Version nur der Nachvollzug der bereits beendeten Tätigkeit.

Wie die erste Strophe bereits ankündigt, orientiert sich Sant Bernharts rosen krentzelin inhaltlich am Crinale, ohne wörtliche Vorlagentreue zum unbedingt einzuhaltenden Äquivalenzkriterium zu erheben. ${ }^{112}$ Dem steht bereits die zusätzliche sechste Zeile entgegen, die einer angemessenen Füllung bedarf. Brant nutzt diesen poetischen Freiraum auf unterschiedliche Weise. In manchen Strophen besteht sein Ehrgeiz darin, die Aussage des lateinischen Prätextes sprachlich auszudehnen, ohne ihren semantischen Gehalt zu verändern. Als Beispiel seien die beiden Eingangsverse der Strophe 14 angeführt: Salve, virga Jesse, florem / Fers, qui coelis dat odorem. Brants Übertragung lautet: Salue rüt von Jesses somen / Die vns bringt den schoinen blumen / Der syn röch jn hymel gytt (14,1-3). ${ }^{113}$ Durch die Erweiterung des kurzen Syntagmas virga Jesse zu einem Substantiv mit anschließender Präpositionalphrase (V. 1), die Auflösung des Enjambements in einen Relativsatz (V. 2) sowie die Ergänzung eines Possessivpronomens und einer Präposition (V. 3) gewinnt Brant zwanglos einen weiteren Vers.

In den meisten Fällen setzt die handschriftliche Version jedoch eigene marianische Akzente. Dabei ergibt sich eine spezifische Ausrichtung des Marienbildes, die mit folgenden - einander ergänzenden und überschneidenden Stichworten umrissen werden kann: Intensivierung, Exemplifikation, Vereinfachung und Intimisierung. Dies sei zumindest kurz ausgeführt.

Im Vergleich zu Konrads Crinale B. M. V. intensiviert Brant die Notsituation des Menschen und die daraus erwachsende Dringlichkeit der Zuwendung Marias. Beispielhaft zitiert seien die letzten beiden Verse der Strophe 48: Audi preces,

112 Damit verwirklicht Brants Crinale-Adaptation eine Übersetzungshaltung, die Kraß im Unterschied zu den sehr freien mittelalterlichen Übertragungen, aber auch in Abweichung von den wortgetreuen ,glossierenden Adaptationen“ als „eher humanistisch genährt“ bezeichnet. Vgl. Kraß: Spielräume, S. 105f. (Zitat: S. 105). Zum Begriff der ,glossierenden Adaptation‘ siehe ebd., S. 104.

113 Basel, Universitätsbibliothek, Cod. A IX 27, fol. 196v 
mater pia, / Tibi supplicantium. Brants Übertragung erweitert diese Aufforderung um einen weiteren Vers: Hör vns mütter die do sygen / Zü dir betten rüffen schrygen / Jn dem ellend vns nit losz. ${ }^{114}$ Zunächst fällt auf, dass das anrufende ,Ich` hier eine andere Sprechhaltung einnimmt. Anstatt sich in distanzierter Weise über die Flehenden zu äußern, artikuliert es durch die doppelte Verwendung des Personalpronomens ( $v n s)$ seine eigene existenzielle Betroffenheit. Zudem wird der abstrakte Nominalstil der Crinale-Strophe (preces; supplicantium) in eine Anzahl von Verben aufgelöst, die das Verhalten der Gläubigen dynamisieren und ihre Bedrängnis zum Ausdruck bringen: Nicht nur fallen sie vor der Gottesmutter nieder (die do sygen); sie steigern sich auch in einen clamor hinein, dessen Vehemenz durch die asyndetische Reihung von drei iterativen, als Klimax angeordneten Verben (betten, ruffen, schrygen) vermittelt wird. Der abschließende Vers stellt eine Amplifikation der lateinischen Vorlage dar. Er verknüpft den Hinweis auf die Exilsituation der Anrufenden mit der emphatischen Aufforderung an die Gottesmutter, sie aus ihrer Verbannung zu befreien. ${ }^{115}$

Eine größere Intensität gewinnt in Brants Adaptation auch die poetische Darstellung des menschlichen Reueschmerzes. Erwähnt sei hier nur Strophe 8 des Crinale, die in den ersten beiden Versen das Dürsten der Gläubigen nach Maria als ihrer Lebensquelle formuliert: Ave vivus fons hortorum, / Quem mens sitit contritorum (8,1f.). Brants amplifizierende Übertragung lautet: Aue tal vnd brunn der garten / Noch dem dirstet vnd düt warten / Das ruwig hertz yemertol (8,1-3). ${ }^{116}$ Zunächst unterstreichen die Zusätze vnd düt warten und yemertol ${ }^{117}$ die anhaltende Bedürftigkeit des Menschen nach Marias Beistand. Darüber hinaus erfolgt eine Ablösung des intellektuell konnotierten Terminus mens durch den emotional besetzten Begriff hertz. Entscheidend für die Ausdruckskraft der deutschen Verse

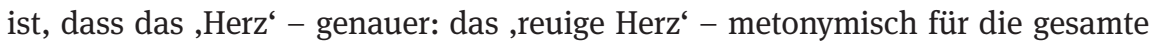
Person eintritt. Durch diese rhetorische Finesse gelingt es Brant, die Absolutheit des Reueschmerzes auf ebenso knappe wie expressive Weise zu versprachlichen.

114 Basel, UB, Cod. A IX 27, fol. $202^{\mathrm{r}}$.

115 Nur erwähnt sei, dass Brant durch seine dreifache Umgestaltung der Vorlage - die Einführung eines kollektiven ,Wir‘, die Dynamisierung der Anrufungssituation und die Betonung des menschlichen Exils - Synergien mit der marianischen Schlussantiphon Salve regina schafft, für deren poetische Gestaltung genau diese Elemente zentral sind. Vgl. zu dieser Antiphon und ihren volkssprachlichen Übertragungen Wegener, Lallinger, Cano Martín-Lara, bes. S. 400-407, 423f. Vgl. ferner die Datenbank des ,Berliner Repertoriums“ (ID: 6941): http://opus.ub.hu-berlin.de/re pertorium/id/6941 (20. September 2019). Es ist anzunehmen, dass die Herstellung und Vertiefung solcher intertextuellen Bezüge ebenfalls zum Profil von Brants Übertragung gehören.

116 Basel, UB, Cod. A IX 27, fol. 196r.

117 iemertol = iemer tâlanc (,immerfort'). 
Der Exemplifikation dienen unter anderem jene semantischen Erweiterungen, die implizite Zusammenhänge verdeutlichen. In Strophe 3 des Crinale wird Maria zunächst als prachtvolle Rose angerufen (V. 1: rosa delicata), die zugleich über alle Himmel erhöht und über die ganze Welt ausgebreitet ist. Die Strophe endet mit dem Wunsch des oder der Anrufenden, dass Maria für die Gläubigen eine schattige Laube sein möge: Sis nobis umbraculum $(3,5)$. Brants Übertragung entfaltet umbraculum zunächst in drei semantisch eng verwandte Begriffe: Bisz vnser schyrm / schätt / geleitte (3,5). Damit wird die Schutzfunktion der Gottesmutter, die der lateinischen Metapher inhäriert, ausdrücklich benannt. Zudem erfolgt durch das Substantiv geleitte eine Dynamisierung Marias, durch die sie stärker auf den Menschen bezogen erscheint. Der letzte Vers $(3,6)$ stellt erneut eine Amplifikation der Vorlage dar: Das der výgend vns nit letz. ${ }^{118}$ Diese Begründung für die menschliche Angewiesenheit auf Marias Zuwendung bietet der lateinische Text nicht. Hier bleibt die Ausdeutung der Metaphorik des Schlussverses dem Rezipienten überlassen.

Zuweilen vereinfacht Brant seine Vorlage, indem er Periphrasen zurücknimmt und komplexe theologische Zusammenhänge auf ihren Glaubensinhalt reduziert. Besonders deutlich wird dies in Strophe 5, welche die Verkündigung an Maria zum Inhalt hat. Im Crinale lautet der zweite Vers: Paranympho salutata. Diese Umschreibung des Engels als ,Brautführer - durch die Konrad dem bekannten Heilsereignis neuen sprachlichen Reiz abgewinnt - vollzieht Brant nicht mit. Er überträgt: Durch den Engel bist gegriesset $(5,2)$. Außerdem vermeidet er die ebenso diffizile wie abstrakte Darstellung der Schwängerung Marias. Im Crinale lauten die entsprechenden Verse: Deo patre obumbrata / Pneumateque impraegnata, / Genitrix verbigenae (5,3-5). Ausführlicher formuliert die deutsche Version: Durch gott vatter vberschatt / Hast das wort ein Jungfrow swanger / Durch den heligen geist entpfangen / Das dir gott gesendet hett (5,3-6). ${ }^{119}$ Zwar bleibt das sprachliche Verständnis aufgrund der Parenthese (ein Jungfrow swanger) und der verschachtelten Zeitstruktur eine Herausforderung, ${ }^{120}$ inhaltlich jedoch ist der Anspruch deutlich geringer als in der lateinischen Vorlage. Die artifizielle Darstellung der Schwängerung als ,pneumatischer' Vorgang (pneumateque impraegnata) ist durch eine eingängige - und überdies im Apostolischen Glaubensbekenntnis kodifizierte - Formulierung ersetzt, die den Heiligen Geist als eigenständige göttliche Person hervortreten lässt. Darüber hinaus wird der problematische

118 Basel, UB, Cod. A IX 27, fol. $195^{\mathrm{r}}$.

119 Basel, UB, Cod. A IX 27, fol. $195^{\mathrm{v}}$.

120 Die im Schlussvers stehende Sendung des Wortes geht dessen Empfängnis durch Maria voraus. Der Rezipient muss diese Vorzeitigkeit erkennen und die einzelnen Aspekte des Heilsereignisses selbst in die richtige Reihenfolge bringen. 
theologische Ausdruck genitrix verbigenae (,Gebärerin des durch das Wort Geborenen') zu der einfachen Aussage, dass Maria das Wort empfangen habe, aufgelöst. ${ }^{121}$

Die Tendenz zur Intimisierung, die sich in Brants Adaptation im Vergleich zu Konrads Mariengruß-Dichtung feststellen lässt, betrifft sowohl das Verhältnis Marias zu Gott bzw. zu ihrem göttlichen Sohn als auch die Beziehung der Gottesmutter zum Menschen. Der Beginn von Crinale-Strophe 30 bezieht sich auf die gegenseitige Nähe von Gott und Maria: Gaude, quia semper tecum / Deus manet et tu secum (30,1f.). Damit bestätigt das anrufende ,Ich` die Unauflöslichkeit der Verbindung, verzichtet aber auf deren qualitative Bestimmung. Die Strophenanapher fordert Maria zwar zur Freude auf; diese ist jedoch nicht genuin mit Marias Gottesnähe verquickt, sondern wird - wie die Konjunktion quia vermittelt - als Resultat des abstrakt formulierten Gegenseitigkeitsverhältnisses erwartet. Dagegen heißt es in den drei Versen der deutschen Adaptation: Gaude dann got by dir blibet / Ewiklich freid mit dir tribet / Vnd din freid ist by jm gantz $(30,1-3){ }^{122}$ Brant nimmt die Strophenanapher also gleich zweimal in den eigentlichen Text mit hinein und bestimmt so die Beziehung zwischen Gott und Maria als eine beiderseitig freudvolle. Indem er dem statischen Verb blîben das dynamische trîben zur Seite stellt, betont er zudem die aktive Zuwendung Gottes, mit der die Vollkommenheit der Freude Marias korrespondiert.

Das jenseitige Verhältnis zwischen dem auferstandenen Christus und seiner verherrlichten Mutter findet in Strophe 7 Erwähnung, die Maria als Himmelsregentin feiert. Der lateinische Text hebt hervor, dass Maria der höchsten Gaben ihres Sohnes würdig sei: Digna summis nati donis, / Quae in coeli regnas thronis, / $O$ regina gloriae (7,3-5). Brants Übertragung behält die Anzahl von drei Versen bei, ersetzt den abstrakten Stil seiner Vorlage jedoch durch einen Sprachduktus, welcher die ,persönliche‘ Wertschätzung Marias durch Christus zum Ausdruck bringt: Din sưn ert mit schönen goben / Jnn des hymels tron do oben / O kynngin der

121 Bereits Prudentius verwendet diesen Ausdruck im dritten Hymnus seines Liber Cathemerinon (Cath. III,2). Problematisch ist er aufgrund der traditionellen Identifikation des Logos mit der zweiten göttlichen Person. Denn diese Gleichsetzung würde bedeuten, dass Christus durch sich selbst geboren ist. Eher jedoch sei - so Pope - an die Hervorbringung des Sohnes durch den intellectus Dei zu denken. Vgl. die Anmerkung zur Textstelle in The Hymns of Prudentius: https:// www.gutenberg.org/files/14959/14959-h/14959-h.htm\#f03_2 (20. September 2019). Ähnlich äußert sich Richardson, S. 91, in seinem Kommentar zur Stelle: „Here, God the Father is Himself identified with the divine Word or Logos, of Whom Christ is begotten.“

122 Basel, UB, Cod. A IX 27, fol. 199. 
eren dich (7,4-6). ${ }^{123}$ Entscheidend für Brants Neuakzentuierung ist die Wiedergabe von natus - die sich in undifferenzierter Weise auf die Sohnesnatur Christi bezieht $^{124}$ - durch die Nominalphrase din suin. Sie definiert Christus eindeutig als Sohn Marias; das Possessivpronomen dient der Artikulation dieses Zugehörigkeitsverhältnisses. Hinzu kommt die Ergänzung des transitiven Verbs êren, ${ }^{125}$ welches die intentionale Ausrichtung Christi auf seine Mutter bekundet.

Wie weiter oben bereits dargestellt, ${ }^{126}$ tritt Marias heilsgeschichtliche Rolle als Mutter Christi im Crinale B. M. V. hinter ihrem Status als Himmelskönigin zurück. Dieser transzendenten Erhöhung entspricht die Konzeption der Grußdichtung als ,Meditationslied', welches durch seine überbordende Bildlichkeit zu einer vertieften marianischen Devotion anregt, ohne der Gottesmutter eine klar umrissene Kontur zu verleihen. In ihrer dem ,glorreichen Rosenkranz' entsprechenden Verherrlichung bleibt sie der Vorstellungskraft des Menschen letztlich entzogen. Brants Adaptation weicht von dieser Ausrichtung des Crinale zwar nicht grundsätzlich ab - zu Recht stellt Knape fest, dass Brant „die Bilderfülle und den poetischen Reichtum der Vorlage [...] im Deutschen gekonnt zu vermitteln“ vermochte $-; 27$ aber sie lässt Marias Zugänglichkeit für die Gläubigen und ihre aktive Menschzuwendung deutlicher hervortreten. Dies zeigt sich zum Beispiel in Strophe 19, welche die meditative Annäherung an die Gottesmutter poetisch gestaltet: ${ }^{128}$

Konrad von Haimburg: Crinale B. M. V.

(AH 3, S. 24)

Salve, cui dulce fari,

De qua pium meditari,

In qua suave jucundari,

Quam beatum amplexari

Est amoris brachiis.
Sebastian Brant: Sant Bernharts rosen krentzelin (Basel, UB, Cod. A IX 27, fol. 197')

Salue die vast güt zuo griessen

Die zü gdencken ist gar siesse

Gybt grosz freid wer sie betraht

Wer dir siesse můtter nahet

Mit syn armen dich vmbfahet

Den hast du bald sellig gmaht.

123 Basel, UB, Cod. A IX 27, fol. 196. Die im Vergleich zum Crinale verschobene Zählung kommt dadurch zustande, dass Brants Übertragung die lateinischen Eingangsverse 7,1f. auf drei Verse (7,1-3) ausdehnt.

124 Der Status Christi als zweite göttliche Person ist hier ebenso inbegriffen wie die Inkarnation. 125 Als zugehöriges Akkusativobjekt dient das Pronomen dich in 7,6, welches ebenfalls dazu beiträgt, der Strophe ein ,persönlicheres‘ Profil zu verleihen. Vgl. dazu auch die weiteren Ausführungen.

126 Vgl. Abschnitt 3, S. 238.

127 Knape, S. 313.

128 Siehe auch oben, Abschnitt 3, S. 235. 
Der lateinische Text ist durchaus emphatisch aufgeladen, insofern er für die spirituelle Vergegenwärtigung der Gottesmutter das amplexus-Motiv wählt (vgl. V. 4f.). Gleichwohl behält die Strophe eine distanzierte Ausdrucksweise bei: Mit Ausnahme der Strophenanapher wird Maria nicht unmittelbar adressiert. Es scheint, dass das anrufende ,Ich' - welches der Gottesmutter seinen geistlichen Blütenkranz in Strophe 1 unbefangen zueignet (vgl. 1,4) - bei der Darstellung der Präsenzerfahrung vor einer direkten Anrede Marias zurückscheut. Brants Adaptation übernimmt in den ersten drei Versen die unpersönlichen Formulierungen der Vorlage. ${ }^{129}$ Im vierten Vers ändert sich die Sprechhaltung des anrufenden ,Ich jedoch: Mit der affektiven Adressierung Marias als ,süße Mutter' wechselt es zur pronominalen Anredeform , $\mathrm{du}^{6}$, die es auch in den folgenden beiden Versen beibehält.

Beide Aspekte - die vertrauliche Anrede Marias und die Betonung ihrer Mutterrolle - sind auch im Crinale vorhanden; in der volkssprachlichen Version werden sie jedoch prononcierter hervorgehoben. In insgesamt sechs Strophen ergänzt Brant die Bezeichnung ,Mutter‘; ${ }^{130}$ in einer weiteren Strophe fügt er sie nach der ersten Nennung ein weiteres Mal hinzu. ${ }^{131}$ Abweichend von Konrads Gedicht setzt der als Imperativ formulierte Schlussvers von Sant Bernharts rosen krentzelin einen finalen Akzent auf Marias Mütterlichkeit: Hilff vns mütter aller meyst $(50,6) .{ }^{132}$ Für die Verstärkung der pronominalen Anrede ,du' sei hier exemplarisch auf Strophe 27 hingewiesen, welche die sternenbekrönte Frau der biblischen Apokalypse auf Maria hin auslegt. ${ }^{133}$ Den abstrakten Partizipialkonstruktionen des Crinale ${ }^{134}$ setzt Brants Adaptation die direkte Adressierung Marias entgegen: Vnder dir der mon duit stan / Allzit blibstu vnverseret / Hast vmbgeben vnd vmbgoret / Jungfrow müter eynen man (27,3-6). ${ }^{135}$

Komplementär zur stärkeren Hervorhebung der Zugänglichkeit Marias nimmt auch ihre Hinwendung zum Menschen in Sant Bernharts rosen krentzelin konkretere Züge an als in Konrads Dichtung. Beispielhaft genannt sei Strophe 10. Statt der unspezifischen Aufforderung des abschließenden Verses His intende precibus

129 Einen zusätzlichen Vers gewinnt Brant dadurch, dass er meditari in zwei unterschiedliche Semantiken entfaltet: Während gdencken den intellektuellen Aspekt zum Ausdruck bringt, erfasst betrahten die affektiv-spirituelle Dimension.

130 Abgesehen von Strophe 19 handelt es sich um die Strophen 10, 13, 18, 27 und 50.

131 Vgl. 24,2; 24,5. Im Crinale bleibt die Bezeichnung mater V. 2 vorbehalten.

132 Basel, UB, Cod. A IX 27, fol. 202\%.

133 Vgl. Apk 12,1.

134 27,3-5: Sub qua luna est locata, / Semper manens illibata, / Cingens virum femina.

135 Basel, UB, Cod. A IX 27, fol. 198/199 ${ }^{\mathrm{r}}$. Die allgemeine Bezeichnung femina im Crinale (27,5; vgl. die vorhergehende Anmerkung) ersetzt Brant durch marienspezifische Anreden (jungfrow, müter). 
$(10,5)$ appelliert die volkssprachliche Version an die Gottesmutter, ihren Blick auf die Gesamtheit der Gläubigen zu richten: Sich an mütter aller tugent / Das die gantz welt zu dir rüfft (10,5 f.). ${ }^{136}$

Als Fazit lässt sich festhalten, dass Maria im Vergleich zum Crinale in Sebastian Brants Dichtung an Plastizität gewinnt. Ohne die Konzeption des lateinischen Prätextes aufzugeben, arbeitet Sant Bernharts rosen krentzelin die sündenbedingte Notsituation des Menschen und die Dringlichkeit der Hilfestellung Marias stärker heraus. Im Gegenzug führt das anrufende ,Ich' den Rezipienten der Grußdichtung vor, dass sie sich ohne Scheu dem Schutz der Gottesmutter anvertrauen dürfen. Diese ist, so eine der impliziten Kernaussagen, in ihrer menschzugewandten Mütterlichkeit stets vertraulich ansprechbar. Garantiert wird Marias Rettungsmacht durch ihre intime Gottesnähe, die aufgrund ihrer poetischen Ausgestaltung als affektiv bestimmtes, intentionales Beziehungsgefüge zugleich die Folie für das Verhältnis zwischen Maria und den Gläubigen darstellt.

\section{Ludwig Mosers Aneignung von Brants Übertragung (Sant Bernarts Rosenkrantz)}

\subsection{Mosers Eingriffe in Basel, UB, Cod. A IX 27}

Weiter oben fand bereits Erwähnung, dass Ludwig Moser Brants Autograph formal und inhaltlich überarbeitet hat. ${ }^{137}$ Die meisten seiner Texteingriffe haben in die Druckfassung der Crinale-Übertragung Eingang gefunden, ${ }^{138}$ die in ihrem eigenständigen Gestaltungswillen allerdings weit über die vergleichsweise dezenten handschriftlichen Korrekturen Mosers hinausgeht. Gleichwohl dokumentieren die Änderungen des Basler Kartäusers eine erste Stufe der Aneignung von Brants Adaptation. Insgesamt finden sich in etwa der Hälfte der Strophen Verbesserungen von Mosers Hand. ${ }^{139}$ Dabei sind grundsätzlich drei Gruppen zu unterscheiden. Bei einer ersten Gruppe handelt es sich um meist minimale Eingriffe, die Moser direkt in den Text eingetragen hat. ${ }^{140}$ Ihnen kommt mit wenigen Ausnahmen

136 Basel, UB, Cod. A IX 27, fol. $196^{\mathrm{r}}$.

137 Vgl. Abschnitt 1, S. 225.

138 Nur bei einer kompletten Änderung des Wortlautes in der Druckfassung finden Mosers Korrekturen keine Berücksichtigung.

139 Siehe zu einer detaillierten Auflistung aller Korrekturen die Apparate von Schmidt (vgl. oben, Abschnitt 1, S. 225) und Wilhelmi (Brant: Kleine Texte, Bd. 1.1, S. 77 f.).

140 Darauf hingewiesen sei, dass Wilhelmi diese Minimalkorrekturen zumindest teilweise Sebastian Brant zuschreibt. Vgl. den Apparat in Brant: Kleine Texte, Bd. 1.1, S. $77 \mathrm{f}$. 
keine Auswirkung auf den Inhalt zu. ${ }^{141}$ So ändert Moser die Schreibweise einzelner Wörter ${ }^{142}$ oder ergänzt Superskripte. ${ }^{143}$ Die zweite Gruppe besteht aus winzigen Korrekturen, die Moser am Seitenrand vermerkt. Ergänzend ist das zu verbessernde Wort im Text unterstrichen. ${ }^{144}$

Von semantischer Relevanz sind vor allem die Eingriffe, die zur dritten Gruppe gehören. Wie jene der zweiten Gruppe bestehen sie aus der Unterstreichung des betroffenen Wortes und einer die Korrektur aufführenden Randnotiz. In mehreren Fällen tauscht Moser innerhalb des Verses einen einzelnen Begriff oder ein kurzes Syntagma aus. ${ }^{145}$ In Strophe 8, Vers 3 hat Mosers Eingriff Auswirkungen auf den Reim. Da er am Versende yemertol durch begirlich ersetzt, muss auch das entsprechende Reimwort geändert werden. Moser tauscht daher in 8,6 vol gegen rich aus. ${ }^{146}$ Nur ausnahmsweise finden innerhalb eines Verses zwei Eingriffe statt. In 11,5 ändert Moser den Vers Hunig siesse gab der fyndet zu Honges siesse waben fyndet. Ungeachtet der Doppelkorrektur (hunig; gab der) bleibt die Silbenzahl konstant - ein Hinweis darauf, dass Moser an die Aufrechterhaltung der Sangbarkeit denkt. ${ }^{147}$ In drei Fällen sind Mosers Randeinträge aufgrund der engen Bindung der Handschrift, die ein Aufschlagen nur begrenzt gestattet, nicht oder nur unvollständig entzifferbar. Die Apparate von Schmidt und Wilhelmi führen

$141 \mathrm{Zu}$ diesen Ausnahmen gehört Strophe 12. Hier ändert Moser in Vers 2 das Adjektiv gantz zum Substantiv glantz. Außerdem korrigiert er in Strophe 12, Vers 4 das Possessivpronomen synem zum Adjektiv fynem. Zuweilen lässt sich durch die Überschreibung der ursprüngliche Wortlaut nicht mehr erkennen (betrifft den in 14,2 sowie lustliche in 31,1).

142 Als Beispiel sei Strophe 6 genannt. Hier ändert Moser in Vers 5 styre zu stúre. Mehrfach korrigiert er die Schreibung der Konjunktion ,dass“ von das zu daz. Vgl. 8,5; 18,4; 20,5; $29,4$.

143 Als Beispiel sei Strophe 14 genannt. Hier ändert Moser in Vers 3 roch zu röch.

144 Hier sind nur vier Strophen betroffen: In 3,2 ändert Moser kynnig zu kûngen und in 3,6 das zu $d z$. In 6,4 korrigiert er fýre zu fhúre und in 13,1 füren zu fhúrin. In der zuletzt genannten Strophe nimmt er zudem einen Genuswechsel vor, indem er in Vers 3 das auf wolck bezogene Relativpronomen der durch die ersetzt. Von inhaltlicher Bedeutung ist nur die Korrektur in 39,2. Hier ändert Moser das Verb verlichen zu verglichen.

145 2,5: Ersetzung von vorgeseit durch vszgekund; 17,3: Ersetzung von kyndes durch knaben; 22,1: Ersetzung von edler durch zarter; 43,5: Ersetzung von du gantz durch sterck vns. Bei der Verbesserung von bin zu din in 40,2 handelt es sich um die Korrektur eines Schreibfehlers.

146 Wilhelmi gibt als Korrektur versehentlich ruh an. Siehe Brant: Kleine Texte 1.1, S. 77 (Apparateintrag zu V. 48).

147 Die Silbenzahl in Brants Übertragung entspricht jener von Salve mater salvatoris (8-8-7-88-7), da diese Sequenz als melodiegebende Vorlage dient. Vgl. oben, Abschnitt 4.2, S. 241. Zur Bedeutung des Silbenzählens für die Gewährleistung der Sangbarkeit volkssprachlicher Liedübertragungen siehe Janota, S. 253. 
die Korrekturen jedoch auf. ${ }^{148}$ Von Bedeutung ist vor allem der massive Eingriff in 29,5. Nur hier tauscht Moser einen kompletten Vers aus. ${ }^{149}$

Bemerkenswert ist, dass Mosers Umgang mit Brants Crinale-Adaptation mit dem titulus der Handschrift korrespondiert, ${ }^{150}$ insofern der Kartäuser Brants Autorschaft durch seine Korrekturen zwar nicht verdrängt - dazu sind diese zu zurückhaltend -, aber einen Aneignungs- und Überlagerungsprozess initiiert. Dieser ist möglicherweise in doppelter Hinsicht durch das spezifische Profil der Handschrift motiviert. Denn zum einen handelt es sich hinsichtlich ihrer volkssprachlichen Texte weitgehend um eine Moser-Handschrift, in welcher der Kartäuser zahlreiche Blätter eigenhändig beschrieben und für die Bewahrung des zweiten Teils seiner Werke gesorgt hat. Auch der titulus macht deutlich, dass der Codex innerhalb der Basler Kartause als Vermächtnis Mosers wahrgenommen wurde. ${ }^{151}$ Gegen diese Überpräsenz Mosers in der Handschrift kommt Brants Autorsignatur nicht an. Durch seine Eingriffe in Brants Übertragung bringt der Kartäuser sein Verfügungsrecht über die in Codex A IX 27 enthaltenen Texte zum Ausdruck. Zum anderen dürfte die weiter oben beschriebene Anlage der Handschrift als ,Werkstattexemplar - die durchaus in Spannung zu ihrem überlieferungssichernden Charakter steht - zur Überarbeitung aller in ihr enthaltenen druckrelevanten Texte eingeladen haben. Der in Brants Signatur dokumentierte Anspruch auf Anerkennung von Sant Bernharts rosen krentzelin als sein geistiges Eigentum konfligiert mit der Vorläufigkeit der Handschrift und tritt letzten Endes hinter ihrer konzeptuellen Beschaffenheit zurück.

Gleichwohl lassen Mosers zurückhaltende, auf Streichungen verzichtende Eingriffe Respekt vor Brants Autograph und seiner poetischen Leistung erkennen. Die tiefgreifende Umformung der Crinale-Adaptation $\mathrm{zu}$ einer eigenständigen, weit von Brants Text abweichenden Fassung fand dementsprechend nicht in Codex A IX 27 statt, sondern in jener verlorengegangenen Handschrift, die als Druckvorlage für Sant Bernarts Rosenkrantz diente.

$148 \mathrm{Zu}$ Schmidts Variantenapparat siehe oben, Abschnitt 1, S. 225. Wilhelmis Apparat führt nur die Korrekturen in Cod. A IX 27 auf. Siehe Brant: Kleine Texte, Bd. 1.1, S. 77 f.

149 Aus Brants Vers Mit dir ewig freid duint tragen wird in Mosers Überarbeitung: ewig lob mit dir betagen. Vgl. Schmidt, S. 54, Anm. 1; Brant: Kleine Texte 1.1, S. 78 (Apparateintrag zu V. 173). Bei den beiden anderen Korrekturen handelt es sich um den Austausch eines Einzelwortes (12,2: gezogen statt gebogen) und eines Syntagmas (19,1: fürpundig statt die vast güt). Vgl. Schmidt, S. 49, Anm. 4; S. 54, Anm. 1; Brant: Kleine Texte 1.1, S. 77 f. (Apparateintrag zu V. 68); S. 78 (Apparateintrag zu V. 109).

150 Siehe dazu oben, Abschnitt 4.1, S. 239 f.

151 Siehe dazu oben, Abschnitt 4.1, ebd. 


\subsection{Mosers an Johannes Amerbach gerichtete Epistula metrica}

Innerhalb der Korrespondenz des eng mit der Basler Kartause verbundenen Druckers Johannes Amerbach ${ }^{152}$ findet sich ein interessantes, auf die CrinaleÜbertragung bezogenes Dokument. Es handelt sich um eine an Amerbach gerichtete, von Ludwig Moser wohl am 8. September 1497 verfasste Epistula metri$c a,{ }^{153}$ die darauf schließen lässt, dass es zu Verzögerungen bei der Drucklegung der Mariengruß-Dichtung kam. Unklar ist, ob sich dieser zeitliche Aufschub auf den gesamten Anhang des Guldin Spiegel des Sunders bezieht ${ }^{154}$ oder nur auf die Crinale-Adaptation als dessen Abschluss. Ebenso im Dunkeln liegt der Grund für den Verzug.

Dass Moser seine Aufforderung an Amerbach, endlich mit dem Druck von Ave, salve, gaude, vale zu beginnen und sich dadurch die Zuwendung der Gottesmutter zu sichern, als dreistrophiges lateinisches Gedicht gestaltet, scheint allerdings mehr zu sein als eine kunstvolle Spielerei. Denn es fällt auf, dass Moser formal einen Schweifreim verwendet, dessen Silbenzahl (8-8-7-8-8-7) sowohl der Sequenz Salve mater salvatoris ${ }^{155}$ als auch Brants handschriftlicher CrinaleAdaptation und deren gedruckter Fassung entspricht. Zur Demonstration sei hier die dritte Strophe der Epistula metrica zitiert, in der Moser den Drucker unter implizitem Verweis auf den biblischen Jakobusbrief zum Handeln drängt:

\footnotetext{
Quare tardas, o impressor?

Si amorum es professor

Dei matris virginis,

Pone manum, non audiitor,

Sed sis facti executor ${ }^{156}$

Coronandus meritis.
}

Aus der Perspektive einer allmählichen Aneignung von Brants Crinale-Übertragung durch den Basler Kartäuser erscheint Mosers lateinisches Gedicht wie ein

152 Vgl. dazu oben, Abschnitt 2, S. 230.

153 Siehe Die Amerbachkorrespondenz, S. 71f., Nr. 63. Das Datum ist erschlossen aus dem Erscheinungsjahr des Guldin Spiegel des Sunders (Drucklegung am 21. Oktober 1497) und der Anspielung auf das Fest Mariä Geburt im Eingangsvers der Epistula metrica: Si ad presens nunc natale (S. 72).

154 Vgl. oben, Abschnitt 1, S. $223 \mathrm{f}$.

155 Allerdings variiert die lateinische Sequenz leicht in der Silbenzahl. Brants Formschema orientiert sich an den ersten vier Versikeln.

156 Jak 1,22: Estote autem factoris verbi et non auditores tantum. Vgl. Die Amerbachkorrespondenz, S. 72, Anm. 3. 
weiterer Schritt auf diesem Weg. Indem er seine namentlich unterzeichnete Aufforderung ${ }^{157}$ zur Drucklegung von Sant Bernarts Rosenkrantz mittels des Formschemas von Sant Bernharts rosen krentzelin formuliert, reklamiert er Brants poetisches Gestaltungsprinzip der Crinale-Übertragung - das in die Druckfassung übernommen wird - für sich selbst.

\subsection{Der Kontext der gedruckten Crinale-Übertragung: Der Guldin Spiegel des Sunders und sein Anhang}

Wie zu Beginn dieses Beitrages bereits erwähnt, besteht der laut Kolophon im Jahre 1497 am Samstag nach St. Lukas (21. Oktober) gedruckte Guldin Spiegel des Sunders aus zwei drucktechnisch voneinander unabhängigen Teilen. Der Hauptteil enthält neben einer Übertragung der Schrift Speculum aureum animae peccatricis des Kartäusers Jacobus van Gruytrode († 1475) drei weitere Texte: einen Beichtspiegel (fol. 90 ${ }^{\mathrm{r}}-130^{\mathrm{r}}$ ), zwölf kurze Erläuterungen zu Sünde, Reue, Sündenvergebung, Beichte und Absolution (fol. $\left.130^{\mathrm{v}}-140^{\mathrm{r}}\right)^{158}$ sowie das auf einem Text des Thomas von Kempen beruhende Rosengertly im trehental (fol. 140 v $-183^{\mathrm{v}}$ ). ${ }^{159}$ Der Anhang bietet drei weitere Übertragungen, die auf dessen erster Seite in einem gesonderten Inhaltsverzeichnis angekündigt werden: einen Cursz vom sacrament (fol. $3^{\mathrm{r}}-27^{\mathrm{r}}$ ), eine Vszlegung des Gloria patri (fol. $27^{\mathrm{v}}-34^{\mathrm{v}}$ ) und abschließend Sant Bernarts Rosenkrantz (fol. $35^{\mathrm{r}}-42^{\mathrm{r}}$ ). Die lateinischen Vorlagen der ersten beiden Texte sind nicht ermittelt. ${ }^{160}$

Offen ist die Frage, ob die Veröffentlichung des Guldin Spiegel als zweiteiliges Werk von vornherein so geplant war. Immerhin fällt auf, dass der Hauptteil keinerlei Hinweis auf die Existenz des Anhangs gibt. Zwar erläutert Moser in seiner Widmungsvorrede an den obersten Zunftmeister der Stadt Basel Nikolaus Rüsch, der den Druck angeregt und vermutlich auch finanziert hat, ${ }^{161}$ den inneren Zusammenhalt der ersten drei Texte des Hauptteils; ${ }^{162}$ er geht jedoch mit keinem

157 Mosers Signatur lautet: Pr. lu. m. cart. cum oracionibus suis. Vgl. Die Amerbachkorrespondenz, S. 72.

158 Die lateinischen Vorlagen dieser beiden Texte sind bisher unbekannt. Vgl. Honemann, S. 155. 159 Siehe oben, Anm. 98.

160 Vgl. Günthart, S. 100. Siehe zum Cursz aber die Hinweise in Anm. 188.

161 Vgl. Günthart, S. 155. Günthart weist darauf hin, dass Rüsch der Basler Kartause ein Exemplar des lateinischen Speculum aureum gestiftet hatte, welches Moser vermutlich als Vorlage für seine Übertragung diente. Ebd., S. 101.

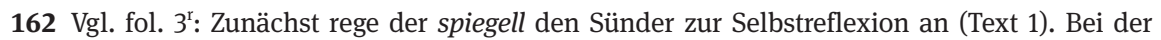
Rekapitulation seiner Laster unterstütze ihn zudem der Beichtspiegel (Text 2; vgl. auch dessen 
Wort auf den vierten Text, das Rosengertly im trehental, ein. Auch den Anhang ignoriert er. Das auf die Vorrede folgende Inhaltsverzeichnis des Hauptteils kündigt dann zwar alle vier hier enthaltenen Texte an (vgl. fol. $4^{\mathrm{r}-\mathrm{v}}$ ), jedoch erneut ohne Hinweis auf den zweiten Teil des Drucks. Erst die Vorrede zum Anhang stellt explizit einen Bezug zum Hauptteil her (fol. $1^{\mathrm{v}}$ : Nach vorgesetzten vnderwysungen [...]) und weist sich damit als unselbständige Publikation aus. ${ }^{163}$

Es mag durchaus sein, dass in den Paratexten des Hauptteils aus verkaufstaktischen Gründen auf die Erwähnung des Anhangs verzichtet wurde. Denn offensichtlich sollte der ,eigentliche‘ Guldin Spiegel unabhängig von den Zusatztexten erwerbbar sein. ${ }^{164}$ Angesichts des in Codex A IX 27 dokumentierten Ringens um die Konzeption der Druckausgabe ${ }^{165}$ scheint es jedoch ebenso möglich, dass die endgültige Textauswahl und deren Arrangement erst nach und nach festgelegt wurden. ${ }^{166}$ Dann hätten sich Spuren dieses Arbeitsprozesses in Vorrede und Inhaltsverzeichnis des Hauptteils erhalten.

Wichtig für die Frage nach der Einbettung der Crinale-Übertragung in die Gesamtpublikation ist zunächst das Verhältnis des Anhangs zum Hauptteil. Auch wenn die Zusammenstellung der drei Zusatztexte vielleicht erst sekundär erfolgt ist, wurde darauf geachtet, sie formal und inhaltlich an den Hauptteil anzubinden. Ersteres erfolgt durch die Verwendung derselben Typen ${ }^{167}$ sowie durch die gleiche Art der Textstrukturierung (Caputzeichen, Einrückungen, als Minuskeln vorgedruckte Lombarden ${ }^{168}$ ). Letzteres wird durch die Vorrede des Anhangs (fol. $1^{v}-2^{v}$ ) bewerkstelligt: Dieser solle, so die Erläuterung, als Hilfestellung dienen, um den stets drohenden Rückfall des bekehrten Sünders in sein vormaliges liederliches Leben mit der Hilfe Gottes und der Gottesmutter Maria zu verhindern.

Vorrede, fol. 90), während ihn die anschließende vffmerckung der sünden (Text 3; vgl. auch dessen Vorrede, fol. $130^{v}$ ) zu Reue, Vergebung und Genugtuung führe.

163 Dass der Anhang als eigenständige Publikation vertrieben wurde, wie Schmidt andeutet (vgl. Anm. 9), erscheint daher zumindest fraglich. In diesem Fall hätte das Inhaltsverzeichnis zugleich als Titelangabe dienen müssen (vorausgesetzt, dass es keine ,Sonderdrucke' mit eigenem Titelblatt gab). Zudem enthält der Anhang kein Kolophon.

164 Darauf lassen die erhaltenen Drucke schließen. Siehe auch oben, Anm. 9.

165 Siehe dazu die Ausführungen in Abschnitt 4.1, S. 240 - 242.

166 Darauf lässt auch jene Notiz in der Handschrift schließen, derzufolge die in den Anhang aufgenommene Auslegung des Gloria patri ursprünglich für den dritten Teil des Spiegel vorgesehen war. Siehe oben, Abschnitt 4.1, S. $241 \mathrm{f}$.

167 Vgl. Die Amerbachkorrespondenz, S. 71, Nr. 63.

168 Diese Kleinbuchstaben wurden beim nachträglichen Eintrag der Lombarden teilweise übermalt, so jedenfalls in den online zugänglichen Digitalisaten des Guldin Spiegel. Vgl. dazu auch Anm. 171. 
Dementsprechend stehen die drei Texte des Anhangs nicht nur mit dem Hauptteil, sondern auch untereinander in einem inneren Zusammenhang: Zunächst diene der Cursz vom sacrament dazu, sich angemessen auf den Sakramentsempfang als zentralen Schutz vor teuflischen Anfechtungen vorzubereiten (vgl. fol. $1^{\mathrm{v}}-2^{\mathrm{r}}$ ). Die folgende Auslegung des Gloria patri leite dazu an, den drei göttlichen Personen verteilt auf die sieben Wochentage Dankbarkeit zu erweisen und so die in der Eucharistie empfangene Gnade zu festigen (vgl. fol. $2^{\mathrm{r}-\mathrm{v}}$ ). ${ }^{169}$ Den Schlusspunkt setze das wirdig lob der iungfrowen Marie gotz muiter, ${ }^{170}$ ohne deren Beistand die göttliche Gnade weder mitgeteilt noch erlangt oder bewahrt werden könne (vgl. fol. $2^{v}$ ). Das Heilsversprechen, das der Guldin Spiegel seinen Rezipienten unter der Voraussetzung einer aktiven Umsetzung seiner pastoralen Unterweisungen gibt, findet so im Mariengruß seine letztgültige Verankerung.

Die Widmungsvorrede zum Guldin Spiegel als Gesamtpublikation ist von Ludwig Mosers Selbstverständnis geprägt, einem laikalen Adressatenkreis innerhalb und außerhalb der Klostermauern den Zugang zu diesem heilszuträglichen Wissen überhaupt erst zu ermöglichen. ${ }^{171}$ Gleich zu Beginn adressiert Moser

169 Die Textreihenfolge ist auch insofern schlüssig, als die Doxologie Gloria patri integraler Bestandteil des Cursz vom sacrament ist. Vgl. z. B. fol. $3^{\mathrm{r}}, 4^{\mathrm{r}}, 10^{\mathrm{v}}$ u. o..

170 Zur Wiedergabe der vollständigen Textstelle siehe Anm. 8.

171 Die laikalen Rezipienten außerhalb der Klostermauern werden durch den Auftraggeber Nikolaus Rüsch repräsentiert. Es handelt sich um eine religiös gebildete, jedoch nicht der akademischen oder humanistischen Elite angehörige Leserschaft, die um die Sicherung ihres Seelenheiles besorgt ist. Innerhalb der Klostermauern dürften vor allem die Laienbrüder der Basler Kartause zu Mosers primärer Nutzergruppe gezählt haben. Jedenfalls verfügte die Laienbibliothek (siehe dazu oben, Abschnitt 2, S. 230 f.) über mindestens fünfzehn gedruckte Exemplare des Guldin Spiegel. Zwölf davon waren eine Schenkung Johannes Amerbachs, die im Liber benefactorum eingetragen ist. Von diesen Druckausgaben ist keine erhalten. Vgl. dazu Honemann, S. 154; Günthart, S. 203; Gilomen-Schenkel: Bücher, S. 35, Nr. 62. Zwei weitere Exemplare (alte Bibliothekssignaturen: D xij und D xv) stiftete Nikolaus Rüsch; ein Exemplar überließ der Kartäuser Heinrich Ecklin seinen Mitbrüdern (alte Bibliothekssignatur: D xviij). Diese drei Drucke, die alle aus Hauptteil und Anhang bestehen, sind noch vorhanden. Vgl. Honemann, S. 153-160; Günthart, S. 203. Digital zugänglich sind der Hauptteil aus D xv (moderne Signatur: Basel, UB, Inc 678) und der Anhang aus D xviij (moderne Signatur: Basel, UB, FP VI 15:1/3): https://doi.org/10.3931/e-rara16322 (9. September 2019); https://doi.org/10.3931/e-rara-15157 (9. September 2019).

Als interne Adressaten treten monastische Rezipienten nur im vierten Text des Hauptteils, dem Rosengertly im trehental, prononciert hervor. Vgl. z. B. fol. $141^{\mathrm{V}}$ die Anrede lieber brider in Verbindung mit der Mahnung, sich dem geistlichen Rat eines tugendhaften Mitbruders anzuvertrauen; fol. $153^{\mathrm{v}}-156^{\mathrm{r}}$ das Kapitel Von gưten geberden eyns demütigen brüders oder fol. $176^{\mathrm{V}}$ das Lob des Schweigens in der Abgeschiedenheit der Zelle. Gleichwohl lässt sich die pastorale Unterweisung des Guldin Spiegel durchgängig sowohl von innerklösterlichen als auch von städtischen Laien auf die jeweils eigenen Lebensumstände übertragen. 
den gonner des Werks Nikolaus Rüsch unter expliziter Nennung seines eigenen Namens:

Dem ersamen fürnemmen Niclaus Růsch By den zitten oberster zunfftmeister der statt Basel / Enbütett brůder Ludwig moser Cartüser ordenns / des Conuendts sant Margaretental ze minderen Basel Costentzer bistumbs / vil heils. (fol. 2')

Anschließend rekapituliert er in starker Stilisierung die Entstehungsgeschichte des Guldin Spiegel: Zunächst sei er von Rüsch gedrängt worden,

die hye nachbestimpten matery vnd Tractetly / von ettlichen andechtigen gottgeliepten brůdern Carthüser ordenns vnd anderen vmb heyl willen eyn yeden sünders / in latin vsz den geschrifften der lerer der heiliger kirchen zů samen gelesen vergriffen / zů tütsch ze machen. (fol. $2^{\mathrm{r}-\mathrm{v}}$ )

In Anerkennung der frommen Gesinnung des obersten Zunftmeisters habe er sich daraufhin selbst vom pastoralen Nutzen der vorgeschlagenen Werke überzeugt und diese anschließend mit dem Einverständnis seines Priors in die Volkssprache übertragen (vgl. fol. $2^{\mathrm{r}}-3^{\mathrm{v}}$ ). ${ }^{172}$

Aufgrund der engen inhaltlichen und formalen Anbindung des Anhangs an den Hauptteil des Guldin Spiegel beansprucht Mosers Vorrede Geltung für alle Texte der Gesamtpublikation. Dadurch aber wird die Crinale-Adaptation in der Wahrnehmung zeitgenössischer Leserinnen und Leser zu Mosers Übertragung einer durch Bernhard von Clairvaux geschaffenen und damit höchste Autorität genießenden Mariendichtung. ${ }^{173}$ Die Aneignung von Brants Werk durch Moser ist damit zu einem Abschluss gelangt.

\subsection{Der Katalogeintrag zu Mosers Schaffen in der Basler Kartause}

Wie erfolgreich Mosers Aneignungsstrategie gewesen ist, erweist ein Eintrag in jenem alphabetisch-systematischen Verzeichnis der Basler Kartäuserbibliothek, welches der mit Moser nicht verwandte Bibliothekar Urban Moser im ersten Jahrzehnt des sechzehnten Jahrhunderts angelegt hat. Unter dem Kürzel $L u$ für

172 Siehe zum Prior Jakob Louber oben, Abschnitt 2, S. 229. Moser erwähnt Loubers Namen nicht und unterstreicht dadurch seine eigene Zentralstellung.

173 Die Zuschreibung des Crinale an Bernhard von Clairvaux (vgl. oben, Anm. 7) stellt ebenfalls eine innere Verbindung zum Hauptteil des Guldin Spiegel her, zu dessen kirchlichen Hauptautoritäten der Zisterzienser zählt. Vgl. fol. $6^{\mathrm{r}}, 8^{\mathrm{r}}, 11^{\mathrm{r}}, 23^{\mathrm{r}}, 24^{\mathrm{v}}, 27^{\mathrm{r}}, 28^{\mathrm{r}} \mathrm{usw}$. 
Ludovicus - ein Hinweis auf die Wertschätzung Ludwig Mosers innerhalb der Basler Kartause $^{174}$ - listet er, teils unter Nennung der deutschen Titel, die Werke Ludwig Mosers auf. ${ }^{175}$ Jene Schriften, die er zur Secunda pars Interpretatorum Eiusdem zählt, sind mit den Nummern 6-15 versehen. Der Beginn des Eintrags lautet: ${ }^{176}$

6 Speculum peccatoris vulgo der Guldin spiegel des súnders

7 Der Cursz vom hochwirdigen Sacrament

8 Vßlegung des Gloria Patris

9 S. Bernharts Rosencrantz.

Hinter diesen vier Titeln steht eine Klammer, auf die sich das Folgende bezieht: $J n$ originali sub littera $E$ 110. In libraria fratrum laicorum sub littera $D$ x. xj. xij. xiij. xiiij. xv. xvj. xvij. xviij. xix.

Die Reihenfolge der Werke entspricht dem Druck. Zwar wird darauf hingewiesen, dass die ,Originale ${ }^{6}$ in Handschrift E 110 enthalten seien, ${ }^{177}$ Sebastian Brants Name fällt in Bezug auf die Crinale-Übertragung jedoch nicht. Deren Titel ist ebenfalls dem Anhang des Spiegel-Druckes entnommen, nicht der Handschrift. Indem der Eintrag unmittelbar nach der Nennung von Codex E 110 die in der Laienbibliothek vorhandenen Drucke aufführt, ${ }^{178}$ erweckt er zudem den Eindruck, dass Handschrift und Druckausgabe inhaltlich identisch sind. Auf diese Weise entsteht die Suggestion, dass alle vier aufgeführten Schriften von Ludwig Moser stammen.

Der Eintrag deutet darauf hin, dass sich in der zeitgenössischen Wahrnehmung die Druckausgabe des Guldin Spiegel vor Codex E 110 (heute: A IX 27) geschoben hat. ${ }^{179}$ Damit jedoch gerät Sebastian Brants handschriftlich dokumen-

174 Vgl. Honemann, S. 145.

175 Der Werkauflistung geht eine kurze preisende Einführung in Mosers Schaffen voraus. Diese stammt von Urban Mosers Nachfolger als Bibliothekar Georg Carpentarius, der den Katalog seines Vorgängers korrigiert und ergänzt hat. Vgl. Burckhardt: Bibliotheksaufbau, S. 36-40 (zum MoserEintrag: S. 37, Anm. 13).

176 Zitiert nach Honemann, S. 146. Den Text bietet auch Günthart, S. 97.

177 Diese Signatur lässt auf eine Zugehörigkeit der Handschrift zur sog. bibliotheca nova schließen. Die ,Wanderung' der Handschrift in die bibliotheca vetus und anschließend in die Laienbibliothek (siehe dazu oben, Abschnitt 4.1, S. 239) findet offenbar erst später statt.

178 Siehe dazu auch Anm. 171.

179 Daher wird auch das ,Original' des Cursz vom hochwirdigen Sacrament Handschrift E 110 zugewiesen, obgleich dieser Text dort nicht enthalten ist. Da der Eintrag zu den Nummern 6-9 ausschließlich auf die Druckausgabe rekurriert, ließe sich vermuten, dass Urban Moser die Handschrift gar nicht eingesehen hat. Dies ist jedoch nicht der Fall, denn er führt im Folgenden 
tierter Anspruch, geistiger Urheber der Crinale-Adaptation $\mathrm{zu}$ sein, in Vergessenheit.

\subsection{Poetischer Anspruch und inhaltliches Profil der in den Druck gelangten Version}

Die bisherigen Ausführungen haben versucht, plausibel zu machen, dass sich Ludwig Moser die Crinale-Übertragung Sebastian Brants auf verschiedenen Ebenen allmählich aneignet. Das inhaltliche Resultat dieses Übernahmeprozesses die eigenständige Fassung Sant Bernarts Rosenkrantz - hat in den bisherigen Erläuterungen jedoch noch keine Berücksichtigung gefunden. Im Folgenden wird diese gedruckte Version in Hinblick auf die Frage analysiert, ob und inwiefern sie Ludwig Mosers Selbstverständnis als Übersetzer reflektiert. Dabei wird sich herausstellen - so viel sei vorwegnehmend gesagt -, dass Moser zwar versucht, Sebastian Brants Werk seinen eigenen Vorstellungen entsprechend $\mathrm{zu}$ transformieren, an diesem Anspruch jedoch scheitert. Paradoxerweise eröffnet ihm dieses Versagen einen Gestaltungsspielraum, den er sich in seinen anderen Übertragungen nicht gestattet.

Wie weiter oben bereits angesprochen, versteht sich Moser als Vermittler heilstheologisch relevanten Wissens an diejenigen, die das latin nit verstanden noch lesen kơnnen (Spiegel-Vorrede, fol. $2^{v}$ ). Sein vorrangiges Äquivalenzkriterium ist möglichst große Nähe zum Ausgangstext. ${ }^{180}$ Explizit artikuliert er dies in seiner Vorrede zum ,Ludwig Moser-Büchlein' ${ }^{181}$ Er habe alle hier enthaltenen Schriften vnuerendert des synns vnd der worten glich so ferr dye gelegenheyt hatt mogen zůlaszen / Jn tütsch gezogen vsz Latyn (iiijb). Günthart weist darauf hin, dass Moser oft derartig wortgetreu übersetze, dass sich seine konkrete Vorlage ermitteln lasse. ${ }^{182}$

Sicherlich kann man dem Basler Kartäuser aus moderner Perspektive vorwerfen, „allzusehr am Wort und an der Konstruktion“ zu kleben. ${ }^{183}$ Angemessener dürfte es jedoch sein, Moser als Seelsorger in absentia zu verstehen, ${ }^{184}$ der für seinen laikalen Adressatenkreis die im Wortlaut der lateinischen Texte enthaltene

Übertragungen Mosers auf, die ausschließlich in der Handschrift überliefert sind. Vgl. die Edition des Katalogeintrags: Honemann, S. 146f.; Günthart, S. 97.

180 Siehe zum Terminus ,Äquivalenz‘ Anm. 25.

181 Vgl. oben, Anm. 48.

182 Vgl. Günthart, S. 109.

183 Ruh: Bonaventura deutsch, S. 190.

184 Vgl. dazu auch oben, Abschnitt 2, S. 228 f. 
Heilswahrheit ohne Abstriche $\mathrm{zu}$ bewahren sucht. Aus seiner monastischen Perspektive muss eine adäquate Übersetzung ${ }^{185}$ pragmatisch auf die Sicherung des Seelenheils bezogen sein, indem sie autoritativ abgesicherte religiöse Unterweisungsliteratur möglichst unverändert in die Volkssprache transferiert. ${ }^{186}$

Der Anspruch des wortgetreuen Übersetzens gilt umso mehr, wenn liturgische oder liturgienahe Inhalte berührt werden. Dies aber trifft vor allem auf den Anhang des Spiegel-Drucks zu. Auf dessen Vorrede folgt ein auf das Altarsakrament ausgerichteter Tagzeitentext, der Cursz vom sacrament, welcher vom Invitatorium der Matutin bis zum Abschluss der Komplet einen Mit- oder Nachvollzug des Officium divinum ermöglicht. ${ }^{187}$ Besonders interessant in Hinblick auf Mosers Aneignung der Crinale-Adaptation ist, dass der Cursz vom sacrament jene vier von Wackernagel edierten Hymnenübersetzungen integriert, die bereits zu Beginn dieses Beitrages Erwähnung fanden: Verbum supernum, Ave vivens hostia, Pange lingua und Veni creator spiritus. ${ }^{188}$ Ein Vergleich von Mosers Übertragungen mit den jeweiligen Hymnen zeigt, dass sein vorrangiges Äquivalenzkriterium der

185 Siehe zum Terminus ,Adäquatheit‘ Anm. 24.

186 Im Falle des Guldin Spiegel erfolgt diese Absicherung auf zwei Ebenen: Zum einen seien die übersetzten Traktate aus Schriften der heiligen Kirchenlehrer zusammengestellt. Zum anderen gehe ihre Kompilation vor allem auf Brüder des Kartäuserordens zurück. Vgl. Vorrede, fol. $2^{r-v}$ (zitiert oben, Abschnitt 5.3, S. 257).

187 Im Dunkeln liegt die intendierte Gebrauchssituation des Cursz vom sacrament. Überhaupt gilt für mittelhochdeutsche Tagzeitentexte, dass ihr ,Sitz im Leben“ noch weitestgehend unerforscht ist. Vgl. Matter, S. 171, 181. Matter gibt in seinem Beitrag Hinweise auf mögliche Gebrauchskontexte und weist in diesem Zusammenhang darauf hin, dass zwischen dem auf ,weltliche“ Laien zugeschnittenen Tagzeitengebet und dem Tagzeitengebet für Laien in geistlichen Gemeinschaften aufgrund der unterschiedlichen Tagesstrukturen zu unterscheiden ist (vgl. S. 183f.). Dementsprechend könnte der Cursz vom sacrament von den Laienbrüdern der Basler Kartause ganz anders genutzt worden sein als von den Spiegel-Rezipienten außerhalb der Klostermauern.

188 Siehe zu Wackernagels Edition und den AH-Nummern der vier Hymnen oben, Anm. 1. Mosers Übersetzungen finden sich auch in Haeller, S. 109-117. Vgl. auch den Eintrag zu Moser in der Datenbank des ,Berliner Repertoriums، (ID: 9791): http://opus.ub.hu-berlin.de/repertorium/ id/9791 (3. Oktober 2019). Unzutreffend ist die Angabe Kraumes (Sp. 706), der Cursz vom sacrament enthalte zehn Hymnenübertragungen Mosers. Vielmehr ist Ave vivens hostia in sieben Abschnitte von zwei bzw. vier Strophen Länge unterteilt, die jeweils mit der Rubrik Der ymps angekündigt werden (Spiegel-Anhang, fol. $11^{\mathrm{v}}-24^{\mathrm{r}}$ ). Bemerkenswert ist, dass die ersten sechs Abschnitte mit einer Doxologie schließen (Incipit: Gloria sy dir herre guit /der vns spisest teglich, fol. 12 $2^{\mathrm{r}}, 13^{\mathrm{v}}, 15^{\mathrm{v}}, 17^{\mathrm{v}}$, $19^{\mathrm{r}}, 22^{\mathrm{r}}$ ), die in AH 31, S. 114, Erwähnung findet. Dort ist zu lesen: „In einem Orationale Campoliliense saec. 15. Cod. Campolilien. 2. ist es [das Lied] verteilt zu einem Cursus de corpore Christi, und zwar für jede Tagzeit je zwei Strophen mit der Doxologie: Gloria tibi, Domine, / Nos pascens cottidie [...]. Diesem Hinweis wäre nachzugehen, um Ludwig Mosers lateinische Vorlage für den Cursz vom sacrament ausfindig zu machen. 
größtmöglichen Nähe zum lateinischen Wortlaut auch für diese lyrischen Texte gilt. $^{189}$

Aussagekräftig ist ein Vergleich der ersten Strophe des Fronleichnamshymnus Pange lingua gloriosi (corporis mysterium) mit den Übertragungen von Sebastian Brant und Ludwig Moser:

Thomas von Aquin (?): Pange lingua gloriosi (corporis mysterium) (AH 50, S. 586)

Pange, lingua, gloriosi

Corporis mysterium

Sanguinisque pretiosi,

Quem in mundi pretium

Fructus ventris generosi

Rex effudit gentium.

Sebastian Brant: Hymnus Pange lingua (ed. Knape, S. 325, nach Basel, UB, Cod. A XI 82, fol. $50^{r}$ )

Min Zung erkling vnd frölich sing

von den zarten lychnam fron

von dem blüt vnd kostlichem ding

das ggossen hat der welt zư lon

frucht des wybes reines lybes

der kung aller völker schon.

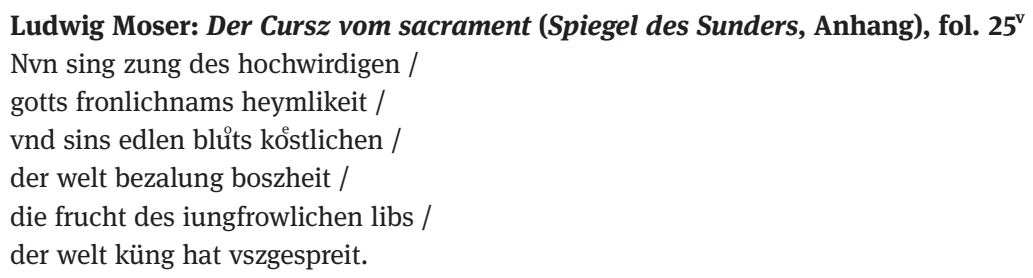

Ludwig Moser: Der Cursz vom sacrament (Spiegel des Sunders, Anhang), fol. $25^{\mathrm{v}}$

Nvn sing zung des hochwirdigen /

gotts fronlichnams heymlikeit /

vnd sins edlen blůts ko̊stlichen /

der welt bezalung boszheit /

die frucht des iungfrowlichen libs /

der welt küng hat vszgespreit.

Brants freier Übertragung, die inhaltliche Nähe zum Ausgangstext mit einer klanglich-ästhetischen Dimension verbindet, setzt Moser einen eng am lateinischen Wortlaut orientierten ,Zungenbrecher` entgegen, der sich nur wenige Abweichungen von der Vorlage gestattet. Als Beispiel sei hier allein Vers 4 genannt, der zugleich Mosers Unvermögen offenbart, Form und Inhalt seiner Übertragung $\mathrm{zu}$ einer stimmigen Einheit zu verbinden. Im Vergleich zum lateinischen Text ergänzt er das Abstraktum boszheit, um zu verdeutlichen, dass Christus die Welt wegen ihrer Sündhaftigkeit durch seinen Tod freikaufen musste. Da er dieses Substantiv aufgrund des Suffixes -heit zudem als Reimwort benötigt, stellt er es

189 In der Ankündigung seiner Pange lingua-Übertragung merkt Moser dies selbst an. Siehe das Zitat unten, Anm. 201. 
ans Versende. Damit aber wird der semantische Zusammenhang von welt und boszheit aufgelöst und muss vom Rezipienten eigenständig rekonstruiert werden.

Es scheint, dass in den beiden Pange lingua-Übertragungen die unterschiedliche Sozialisation ihrer Autoren zum Ausdruck kommt: Dem humanistischen Ehrgeiz Brants, den Inhalt der Vorlage in einer ästhetisch ansprechenden Form darzubieten, ${ }^{190}$ tritt das monastische Anliegen Mosers gegenüber, seinen Rezipienten eine möglichst authentische Teilhabe am Officium divinum $\mathrm{zu}$ ermöglichen. ${ }^{191}$

Umso erstaunlicher wirkt es zunächst, dass Ludwig Moser das Crinale B. M. V. Konrads von Haimburg nicht komplett eigenständig übersetzt hat. Im Falle des Pange lingua hielt er dies offenbar für unabdingbar, obwohl er Sebastian Brants Adaptation dieses Hymnus sicherlich zur Kenntnis genommen hat. ${ }^{192}$ Seine Prosaübertragungen sind ebenfalls grundsätzlich unabhängig von bereits vorliegenden Übertragungen entstanden. ${ }^{193}$ Dies gilt auch für den ersten Teil des Guldin Spiegel des Sunders. ${ }^{194}$

Der primäre Grund für Mosers Unselbständigkeit bei der Übertragung von Ave, salve, gaude, vale dürfte darin zu suchen sein, dass Brant mit seiner Adaptation etwas geleistet hat, wozu sich der an Prosatexten geschulte Basler Kartäuser außerstande sieht: Durch die Verwendung des sechszeiligen Strophenschemas der Sequenz Salve mater salvatoris stellt Brant Sangbarkeit her und bindet das Crinale so an die Liturgie zurück. ${ }^{195}$ Die ,private‘ Rosenkranzfröm-

190 Vgl. auch oben, Abschnitt 4.2, S. 243 f.

191 Siehe zur Einwirkung unterschiedlicher sozialer Gegebenheiten auf das Liedschaffen auch Janota, S. 261.

192 Brants Übertragung dürfte laut Knape, S. 324, ca. 1491 entstanden sein. Sie lag also bereits vor, als der Spiegel-Druck vorbereitet wurde. Ein formales Detail verrät möglicherweise, dass Moser die Adaptation Brants nicht nur kannte, sondern genau studiert hat. Während der lateinische Hymnus aus Kreuzreimen (ababab) besteht, wählt Brant ein davon abweichendes Reimschema: ababcb. Dasselbe Schema verwendet Moser.Vgl. oben die Wiedergabe der ersten Strophe. Wie es häufiger in Mosers Hymnenübertragungen, aber auch in seiner Crinale-Fassung vorkommt, sind Vers 1 und 3 nur durch einen Endsilbenreim aufeinander bezogen. Die Binnenreime in Brants Fassung (vgl. Strophe 1, V. 1, V. 5) hat Moser nicht zur Kenntnis genommen oder ignoriert. Siehe zu Brants Pange lingua-Übertragung auch Knape, S. 314.

193 Vgl. Günthart, S. 116.

194 Dieser beruht - wie bereits angemerkt - auf dem Speculum aureum animae peccatricis des Kartäusers Jacobus van Gruitrode. Eine erste Übertragung dieses Traktats, die auch handschriftlich überliefert ist, wurde 1484 und 1487 in der Ulmer Offizin von Konrad Dinckmut gedruckt. Vgl. Ruh: ,Der goldene Spiegel', Sp. 91; Günthart, S. $100 \mathrm{f}$.

195 Siehe dazu auch oben, Abschnitt 4.2, S. 243. Dass die liturgische Rückbindung über die Sequenz Salve mater salvatoris erfolgt, mag an deren fester Verankerung im Kreis der Marienfeste und der daraus resultierenden Bekanntheit liegen. Siehe den Eintrag zu Salve mater salvatoris in 
migkeit, der sowohl Brant als auch Moser die Mariengruß-Dichtung zuordnen, ${ }^{196}$ wird auf diese Weise liturgisch geadelt. ${ }^{197}$

Wie sehr Moser an diesem durch Brants formalen Eingriff bewirkten Dignitätsgewinn der Crinale-Übertragung liegt, lässt sich der Überschrift zu Sant Bernarts Rosenkrantz entnehmen, die explizit auf Salve mater salvatoris als melodiegebende Sequenz hinweist. ${ }^{198}$ Erinnert sei zudem an Mosers Epistula metrica, welche die Aufforderung zur Drucklegung der Mariengruß-Dichtung mittels des Sechs-Zeilen-Schemas von Brants Adaptation formuliert. ${ }^{199}$ Die Rückbindung der Crinale-Übertragung an das Officium divinum legitimiert ihre Aufnahme in den liturgisch ausgerichteten Anhang zum Guldin Spiegel des Sunders ${ }^{200}$ und kommt dem Bedürfnis weltlicher wie geistlicher Laien nach Partizipation an der institutionell-sakralen Sphäre entgegen. ${ }^{201}$

Allerdings kollidiert Brants freie poetische Gestaltung seiner Crinale-Übertragung mit Mosers Postulat möglichster Ausgangstextnähe. Diese Diskrepanz dürfte den Basler Kartäuser dazu veranlasst haben, massiv in die bereits vorlie-

der Datenbank des ,Berliner Repertoriums‘ (vgl. Anm. 108). Es sei zudem darauf hingewiesen, dass zwischen dem Crinale und der Sequenz inhaltliche Synergien bestehen, die sich nur schwierig mit dem Rückgriff Konrads von Haimburg und Adams von St. Viktor auf dasselbe Inventar marianischer Topoi erklären lassen. Man vergleiche etwa die begrifflichen Übereinstimmungen von Crinale, Strophe 41/42, mit Salve mater salvatoris, Versikel 5/Gegenversikel 6. Möglicherweise hat sich Konrad von Haimburg bei der Abfassung des Crinale von der zeitlich vorgängigen Sequenz inspirieren lassen. Jedenfalls bestehen zwischen seiner Mariengruß-Dichtung und Salve mater salvatoris deutliche intertextuelle Bezüge, die in Brants volkssprachlicher Version durch die Melodieübernahme zusätzlich unterstrichen werden.

196 Vgl. oben, Abschnitt 3, S. 233.

197 Von der liturgisch-institutionellen Rückbindung des ,privaten` Rosenkranzgebetes legen auch andere Ausdrucksformen spätmittelalterlicher Frömmigkeit Zeugnis ab, etwa bildliche Darstellungen, welche den Rosenkranz mit dem Messgeschehen in Verbindung setzen. Vgl. dazu Lentes, S. 82-87. Eine differenzierte Auseinandersetzung mit den Beschreibungskategorien ,liturgisch" und ,privat' bietet Rothenberger, S. 293-309.

198 Zitiert oben, Abschnitt 4.2, S. 243.

199 Siehe oben, Abschnitt 5.2.

200 Auch dessen zweiter Text, die Auslegung der Doxologie Gloria patri, entspricht dieser liturgischen Orientierung. Vgl. auch oben, Anm. 169.

201 Greifbar wird dieses Bedürfnis zum Beispiel in den speziellen Konversen-Liturgien, die in der Laienbibliothek der Basler Kartause zugänglich waren. Vgl. Honemann, S. 263f. Darauf hingewiesen sei, dass sowohl Moser als auch Brant bei ihren Pange lingua-Übertragungen deren Sangbarkeit hervorheben. Moser kündigt seine Übertragung im Cursz vom sacrament (SpiegelAnhang, fol. $25^{v}$ ) mit den Worten an: Der ymps Pange lingua / so man zur vesper zitt singt vom heiligen sacrament glich mit worten vnd mit der melodig. Siehe zu Brants Sangbarkeitsanspruch Knape, S. 314, 324. 
gende Adaptation einzugreifen. ${ }^{202}$ Von den fünfzig Strophen sind nur fünf wortgleich oder mit winzigen Abweichungen aus Brants Autograph übernommen. ${ }^{203}$ Zwanzig weitere Strophen orientieren sich eng am Referenztext, weichen jedoch bei einzelnen Begriffen oder Syntagmen von ihm ab. Zuweilen wird ein einzelner Vers ausgetauscht. ${ }^{204}$ In zwölf Strophen sind mindestens zwei, in der Regel jedoch drei oder mehr Verse vollständig umformuliert worden. ${ }^{205}$ Dreizehn Strophen weisen keine oder fast keine Berührungen mit dem Referenztext auf. ${ }^{206}$

In einigen Fällen gelingt die Angleichung der gedruckten Crinale-Adaptation an den lateinischen Prätext durch gezielte Eingriffe in den Wortbestand, ohne die Gesamtkonzeption der Strophe zu verändern. Beispiele hierfür sind die Strophen 2, 6 und 27. In Strophe 2 wird der abschließende Vers ausgetauscht. ${ }^{207}$ Er bezieht sich auf das Gottesverhältnis Marias und lautet im Lateinischen: Dei placens oculis $(2,5){ }^{208}$ Brants volkssprachliche Version rekurriert stattdessen auf Marias Erwählung: Hat dich gott jm selb bereit $(2,6)$. In der gedruckten Fassung erfolgt ohne Änderung des Reimes - die Rückbindung an den lateinischen Text: Bist gotts ougen gfellikeit $(2,6)$. Ein ähnlicher Eingriff findet sich in den beiden Schlussversen der sechsten Strophe. ${ }^{209}$ Im Crinale artikuliert das anrufende ,Ich ${ }^{6}$ in abstrakt-allgemeiner Formulierung seine Jenseitshoffnung: Per te simus, advocata, / Coelici indigenae (6,4f.). Dagegen wird die Gottesmutter in Brants Übertragung dazu aufgefordert, sich aktiv für die Rettung des Menschen einzusetzen: Durch din fúrbitt hilff vnd styre / Mach vns aller súnden fry (6,5f.). Die Druckfassung übernimmt diese imperativische Formulierung ebenso wie die Dynamisierung der Rolle Marias. Aber sie integriert die transzendente Perspektive des Crinale, indem das anrufende ,Ich` die Hilfestellung Marias auf den jenseitigen Wohnsitz der

202 Bereits Rajewski ist die größere Ausgangstextnähe von Mosers Adaptation aufgefallen. Sie bietet auf S. 165-176 eine synoptische Gegenüberstellung der beiden Versionen (deren Transkription allerdings nicht fehlerfrei ist). Unter A ist Mosers Fassung vollständig wiedergegeben, unter B wird Brants handschriftliche Übertragung - ohne Mosers Korrekturen - abgedruckt. Rajewski nimmt eine Vorgängigkeit von A (Moser) an, während B (Brant) die bereits vorliegende Adaptation mit Hilfe des lateinischen Textes stilistisch und metrisch geglättet habe. Diese Notwendigkeit habe sich aus der engen Orientierung von A (Moser) am lateinischen Wortlaut ergeben: ,[...] $A$ translated directy, and rather poorly from the Latin“ (S. 176).

203 Vgl. Strophen 9, 18, 24, 31, 36. Die Übernahme erfolgte nicht unmittelbar, sondern über eine verlorengegangene Handschrift. Siehe dazu oben, Abschnitt 4.1, S. 242.

204 Vgl. Strophen 2, 3, 4, 6, 7, 8, 11, 12, 14, 15, 16, 17, 22, 23, 26, 27, 28, 42, 43, 46.

205 Vgl. Strophen 1, 10, 20, 30, 33, 34, 37, 40, 41, 44, 45, 49.

206 Vgl. Strophen 5, 13, 19, 21, 25, 29, 32, 35, 38, 39, 47, 48, 50.

207 Daneben finden sich noch zwei kleinere Änderungen in V. 2 und V. 5.

208 Vgl. oben, Abschnitt 3, S. 237.

209 Leicht abgeändert werden außerdem die Verse 2 und 4. 
Gläubigen bezieht: Durch din fürbitt hilff vnd stüre / Mach vns hymelsch burger syn (6,5f.). In Strophe 27, die Maria als apokalyptische Frau tituliert, ${ }^{210}$ bezieht sich das Angleichungsbestreben auf die ersten beiden Verse. Sie rufen die Gottesmutter als Sternengekrönte, mit dem Sonnenlicht Umkleidete an: Gaude stellis coronata, / Solis luce trabeata (27,1f.). Sebastian Brant hält sich hier eng an seine lateinische Vorlage, wählt für das Partizipialadjektiv coronatus jedoch eine freiere Übersetzung: Gaude mit sternen gezieret / Mit der sunnen schyn vmbfieret (27,1f.). Moser aber liegt daran, das Herrschaftsinsignium der Krone hervorzuheben: Gaude gekrönt mit sternen kron / Mitt sunnen glantz vmbfüret schon (27,1f.). Die Änderung des Reimwortes fängt seine Fassung durch das Füllwort schon auf; außerdem erlaubt er sich, das Substantiv schyn durch den ausdrucksstärkeren Begriff glantz zu ersetzen.

Eine derartig unproblematische Rückbindung von Brants Crinale-Adaptation an Konrads Mariengruß-Dichtung ist Moser allerdings nur in wenigen Fällen möglich. In der Regel sieht er sich durch seine Angleichungsversuche zu größeren Eingriffen auf semantischer, grammatischer und metrischer Ebene gezwungen. Dabei ergibt sich für ihn immer wieder das Problem, sein vorrangiges Äquivalenzkriterium der wörtlichen Übersetzung mit dem aus Salve mater salvatoris übernommenen Sechs-Zeilen-Schema in Einklang bringen zu müssen. An dieser Anforderung scheitert Moser, allerdings auf ebenso produktive wie kreative Weise. Denn in der formalen Vorgabe, die Bilderfülle des Crinale in einen volkssprachlichen Schweifreim umzusetzen, liegt nicht nur eine Gefährdung von Mosers striktem Übersetzungsprinzip, sondern auch eine Verführung zur freien poetischen Gestaltung. Dieser schöpferische Spielraum ist in doppelter Hinsicht legitimiert: zum einen durch die Unaufgebbarkeit des Sechs-Zeilen-Schemas; zum anderen aber auch dadurch, dass es sich bei der Mariengruß-Dichtung ungeachtet ihrer formalen Rückbindung an die Liturgie dennoch um keinen liturgischen oder liturgienahen Text im engeren Sinne handelt. Anders als die vier Hymnenübertragungen im Cursz vom Sacrament, die funktional auf den Mit- oder Nachvollzug des Officium divinum ausgerichtet sind, bleibt Sant Bernarts Rosenkrantz ein poetischer Ausdruck für die - in die sakral-institutionelle Sphäre eingebundene ,private‘ Rosenkranzfrömmigkeit seiner laikalen Rezipienten. Daher büßt Mosers verbum de verbo-Prinzip in Bezug auf diesen Text seine unbedingte Gültigkeit ein.

Vor dem Hintergrund dieser Überlegungen lässt sich der Crinale-Adaptation Sebastian Brants hinsichtlich ihrer Aneignung durch Ludwig Moser eine paradoxe Rolle zuschreiben: Einerseits fungiert sie als Gerüst für Mosers eigene Fassung. An ihr orientiert und schult der Basler Kartäuser sich, um seinen Anspruch erfüllen

210 Vgl. oben, Abschnitt 4.2, S. 249. 
zu können, eine in das Gesamtkonzept des Guldin Spiegel passende CrinaleÜbertragung zu schaffen. Andererseits wirkt sie als Stimulans, sich von ihr zu lösen, um den gestalterischen Freiraum des Sechs-Zeilen-Schemas selbständig zu nutzen. Aus dieser Widersprüchlichkeit erwächst die Hybridität der gedruckten Crinale-Übertragung, ${ }^{211}$ die Brants Adaptation zwar immer wieder als Folie durchscheinen lässt, aber über weite Strecken eigene Wege beschreitet.

Eine ausführliche Analyse von Sant Bernarts Rosenkrantz lässt sich im gegebenen Rahmen nicht leisten. Im Anschluss an die vorangehenden Ausführungen seien jedoch drei durchgängige Tendenzen genannt, die Mosers Transformationsleistung im Vergleich zu Brants Crinale-Adaptation konkretisieren.

Wie weiter oben bereits dargelegt, weichen zahlreiche Strophen der Druckfassung nur geringfügig von Sant Bernharts rosen krentzelin ab. Sie beschränken sich darauf, einzelne Begriffe oder Syntagmen zu ergänzen oder zu ersetzen. Manche dieser Eingriffe dienen der Angleichung an den lateinischen Text. In anderen aber gelangt ein Intensivierungs- und Überbietungsbestreben zum Ausdruck, welches Mosers Fassung in ein Konkurrenzverhältnis zu ihrem Referenztext setzt. ${ }^{212}$ Nur wenige Beispiele seien hier aufgeführt: In Strophe 7, Vers 1 wird Maria in Brants Adaptation mit den Worten gegrüßt: Aue mütter Salomonis. Dies entspricht dem lateinischen Prätext (Ave mater Salomonis). Die Druckfassung fügt den Herrschaftsstatus Salomos hinzu: Aue muiter küng salomons. Zentrales Thema der fünfzehnten Strophe ist Marias Unberührtheit vom Joch Evas, unter Schmerzen gebären zu müssen. In freier Aneignung seiner Vorlage formuliert Brant im letzten Vers, dass Maria ihren Sohn durch gottes krafft zur Welt gebracht habe. Moser übernimmt den Wortlaut der gesamten Strophe weitestgehend, verstärkt aber im letzten Vers das Moment des Außeralltäglichen: Die Geburt Christi sei durch gotts wunder krafft erfolgt (15,6). Strophe 6 stellt einen typologischen Bezug zwischen Maria und dem brennenden Dornbusch (vgl. Ex. 3,2) her. Den lateinischen Vers Igne sacro inflammata $(6,3)$ setzt Brants Adaptation in eine pronominale Anrede der Gottesmutter um: Du entflambte von gots fýre $(6,4)$. Die Druckfassung behält die Sprechhaltung des anrufenden ,Ich' bei, betont aber die vollkommene Durchdringung Marias von Gott: Du durchglügend von gotts fhüre $(6,4)$.

Die Strophen, die sich weiter vom Referenztext entfernen, entwickeln zumindest ansatzweise ein eigenes marianisches Profil. So intensiviert Mosers

211 Vgl. oben, Abschnitt 1, S. 226.

212 Vgl. zum Aspekt der Konkurrenz von volkssprachlichen Übertragungen marianischer Dichtung (diskutiert am Beispiel der Sequenz Ave praeclara maris stella) Kraß: ,Ich gruess dich gerne', bes. S. $313 \mathrm{f}$. 
Fassung die affektive Hinwendung des anrufenden ,Ich` zur Gottesmutter und hebt deren stete Gegenwart im Inneren der Gläubigen hervor. Exemplarisch sei Strophe 19 genannt, die in Hinblick auf Brants Adaptation bereits ausführlicher besprochen worden ist. ${ }^{213}$ Hier lautet der Text der gedruckten Crinale-Fassung:

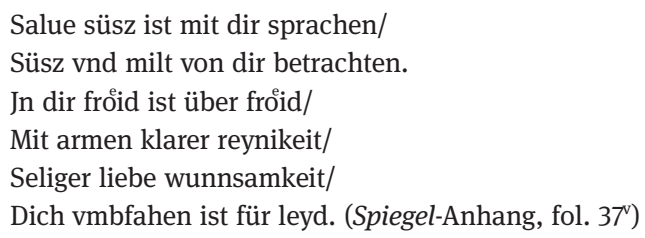

Abweichend von Brants Version, die in den ersten drei Versen die unpersönliche Ausdrucksweise des Crinale beibehält, wählt das anrufende ,Ich`in Mosers Fassung bereits im Eingangsvers die vertrauliche Anrede ,du'. Besonders auffallend ist die eindringliche Ausgestaltung des amplexus-Motivs im zweiten Teil der Strophe. Auch Brants Übertragung nutzt dieses Motiv, um die größtmögliche Nähe des Gläubigen zur Gottesmutter darzustellen. Die Vollendung der geistlichen Umarmung liegt hier jedoch nicht in der Macht des Menschen. Dieser kann sich zwar in seiner Betrachtung auf Maria zubewegen, bleibt aber auf deren Beistand angewiesen: Wer dir siesse mutter nahet / Mit syn armen dich vmbfahet / Den hast $d u$ bald sellig gmaht (19,4-6). Mosers Fassung dagegen verzichtet auf diese Einschränkung. Vielmehr gesteht sie dem Gläubigen die Möglichkeit zu, in der meditativen Versenkung den Makel der Sünde zu überwinden. Dieser Zustand innerer ,Reinheit‘ verschränkt sich mit der unbedingten Liebe zur Gottesmutter, die in der geistlichen Umarmung ihre Erfüllung findet. Maria ist in der Konzeption der Strophe zwar ein Hort überschwänglicher Freude; diese wird von ihr jedoch nicht mitgeteilt, sondern vom Gläubigen im amplexus erreicht. ${ }^{214}$

Als zweites Beispiel sei Strophe 30 angeführt, die ebenfalls schon in Bezug auf Brants Adaptation behandelt worden ist. ${ }^{215}$ Sie hat in Mosers Fassung folgenden Wortlaut:

Gaude dz gott ewiglich blipt/

By dir vnd du by im / vnd tribt

213 Vgl. oben, Abschnitt 4.2, S. 248f. Siehe außerdem Abschnitt 3, S. 235.

214 Mosers spezifische Ausgestaltung der Strophe, die ihren Fokus auf das distanzüberwindende Potenzial der Liebe richtet, korrespondiert mit den ,mystischen' Passagen im Rosengertly, dem vierten Text im Hauptteil des Spiegel-Drucks (vgl. oben, Abschnitt 5.3, S. 254). Vgl. z.B. ebd., fol. 166 .

215 Vgl. oben, Abschnitt 4.2, S. 247. 
Froid mit dir in liebe pflicht/

Durch in ich bitt bisz stet by mir/

Erlücht myn hertz vnd myn begir/

Mit dem liecht dyner angsicht. (Spiegel-Anhang, fol. $39^{\mathrm{r}-\mathrm{v}}$ )

An der Strophe lässt sich exemplarisch aufzeigen, dass Moser während seiner Arbeit auf verschiedene Vorlagen zurückgreift, die er gegebenenfalls miteinander kombiniert und an das marianische Profil seiner eigenen Fassung angleicht. Der erste Vers und der Anfangsteil des zweiten Verses (bis zur Virgel) entsprechen dem Crinale: Gaude, quia semper tecum / Deus manet et tu secum (30,1f.). Die Passage unterstreicht die unauflösliche wechselseitige Bezogenheit von Gott und Maria. Das folgende Enjambement (V. 2f.) ist durch Brants Adaptation angeregt. Übernommen werden das Verb trîben und das Substantiv vröude, um die Dynamik und positive Beschaffenheit des Gegenseitigkeitsverhältnisses zum Ausdruck zu bringen. Das Syntagma in liebe pflicht intensiviert die Hinwendung Gottes zu Maria und stellt zudem eine Übersteigerung des Referenztextes dar. Die Verse 4-6 wechseln die Perspektive, indem sie sich der Beziehung zwischen Maria und dem anrufenden ,Ich` zuwenden. Die Orientierung erfolgt nun wieder am lateinischen Text, der im Unterschied zu Brants Version die Präsenz Marias im Inneren des Menschen hervorhebt: Per quem [deum] precor, ut sis mecum, / Et cor meum lustres tecum / Vultus tui lumine (30,3-5). ${ }^{216}$ Im Vergleich zum Crinale intensiviert und dynamisiert Vers 5 den Wunsch des anrufenden ,Ich` nach Erleuchtung durch Maria: Denn dem emotional besetzten, aber statischen Begriff ,Herz' wird die ,Begierde' als Ausdruck für das intentionale Streben des Menschen zur Seite gestellt. Diese Amplifikation dürfte durch eine dritte Vorlage neben dem lateinischen Text und Brants Übertragung angeregt worden sein: In der Crinale-Adaptation Heinrich Laufenbergs lautet der entsprechende Vers: erlüht min hercz, daz ist min gir $(30,4) .{ }^{217}$ Verschiedentlich finden sich in Sant Bernarts Rosenkrantz Anklänge an Laufenbergs Text, die darauf schließen lassen, dass dessen Lieder in der Basler Kartause bekannt waren. ${ }^{218}$

216 Brant versteht das lateinische Verb lustrare nicht im Sinne von ,beleuchten', sondern von ,besichtigen/betrachten'. Seine Übertragung fokussiert die durch Maria zu überstrahlende Sündhaftigkeit des Menschen, durch die trotz der Intimisierungstendenz (vgl. oben, Abschnitt 4.2, S. 247 f.) immer ein Moment der Distanz zur Gottesmutter erhalten bleibt: Durch den [got] bitt ich dich jungfrowen / Wellst myn blyndes hertz beschowen / Mit dins angesiehtes glantz (30,4-6). 217 Wackernagel 2, S. 551. Zum gesamten Liedtext siehe ebd., S. 550-553, Nr. 727.

218 Siehe zur Verbreitung, sozialen Verortung und Rezeption von Heinrichs Liedern Nemes, S. 81-88. Vgl. außerdem Wachinger, S. 331-336 (zum Aufbau der 1870 verbrannten Liederhandschrift B $1214^{\circ}$, die auch die Crinale-Adaptation enthielt). Dass Sebastian Brants Übertragung der Sequenz Ave praeclara maris stella Anleihen bei Heinrich nimmt, ist seit Brinkmanns grundle- 
Neben den durchgängigen Tendenzen eines Intensivierungs- und Überbietungsstrebens im Vergleich zu Brants Crinale-Übertragung sowie der ansatzweisen Profilierung eines eigenen Marienbildes sei noch eine dritte Tendenz der gedruckten Fassung benannt, die in jenen Strophen greifbar wird, die keine oder kaum Berührungen mit Brants Version aufweisen ${ }^{219}$ und sich zugleich vom lateinischen Text entfernen. In diesen Strophen tritt - in unterschiedlicher Ausprägung - ein poetisches Emanzipationsbestreben zutage, welches sich sowohl auf die lateinische Vorlage als auch auf Brants Adaptation bezieht, und Mosers vorrangiges Äquivalenzkriterium der möglichst wortgenauen Orientierung am Ausgangstext ganz oder weitestgehend außer Kraft setzt. Diese Strophen zeugen von einer Lust an der freien poetischen Gestaltung, die sich Bahn bricht, ohne von Mosers monastischer Haltung in die Schranken gewiesen zu werden.

\section{Fazit}

Aus moderner Perspektive mag man Mosers schrittweise Aneignung von Sebastian Brants Crinale-Übertragung für moralisch unlauter ${ }^{220}$ und Sant Bernarts Rosenkrantz für ästhetisch minderwertig halten. ${ }^{221}$ Zudem könnte man dazu geneigt sein, Mosers Vorgehen als skurrilen Einzelfall abzutun.

Tatsächlich jedoch spiegelt sich in Mosers Crinale-Adaptation ein kultureller Konflikt wider, der im fünfzehnten Jahrhundert auf verschiedenen Ebenen ausgetragen wird. Es geht um die stets von neuem auszuhandelnde Problematik, wie sich monastisches Demutsideal und humanistischer Selbstdarstellungsanspruch miteinander vereinbaren lassen. Verschärft stellt sich diese Frage innerhalb der Ordensreformbewegungen, die auf zahlreiche Gelehrte wie ein Magnet wirkten, ${ }^{222}$ obgleich sie zur Regeltreue verpflichteten und mit Nachdruck die Einhaltung der klösterlichen Grundtugenden Demut und Gehorsam forderten. Dem „Spannungsfeld, das sich zwischen ,Demut' und Bildung auftut“, widmen sich zum Beispiel die Schriften des Melker Priors Johannes Schlitpacher. ${ }^{223}$

gendem Beitrag bekannt. Vgl. ebd., S. 26-28. Siehe auch Knape, S. 318f.; Kraß: ,Ich gruess dich gerne', S. 311 f.; Nemes, S. 85 f.; Rothenberger, S. 268-291, bes. S. 285 f.

219 Vgl. oben, S. 264.

220 Eine negative Reaktion Brants ist allerdings nicht überliefert.

221 So konstatiert Appelhans, S. 40, dass jeder künstlerische Anspruch der Übertragung an ,der bescheidenen Sprachkraft und dem mangelnden Formgefühl“ ihres Schöpfers scheitere.

222 Als Beispiel genannt sei die sog. Melker Reform des Benediktinerordens, die untrennbar mit der Wiener Universität verbunden ist. Vgl. Groiss 1999, S. 150-158; Glassner 2013, S. 82-84.

223 Niederkorn-Bruck, S. 89. 
Die gleiche Problematik gilt für den Kartäuserorden, dessen Selbstverständnis von dem Schlagwort geprägt war: Cartusia numquam reformata, quia numquam deformata. ${ }^{224}$ In Mosers unmittelbarem Lebensumfeld, der Basler Kartause, kam es zu Auseinandersetzungen, weil der Prior Jakob Louber dem berühmten Gelehrten Johannes Heynlin von Stein nach dessen Eintritt keinerlei Sonderrechte zugestehen wollte. ${ }^{225}$ Als Heynlin 1496 starb, verfasste der besonders eng mit ihm verbundene Sebastian Brant ein dreizehn elegische Distichen umfassendes Gedicht für sein Grabmal. Allerdings bestand Louber auf einem schlichten Begräbnis ohne Epitaph. ${ }^{226}$ Ungeachtet dieser Einschränkungen stand Heynlin auch nach seinem Klostereintritt im Zentrum des Basler Humanistenkreises. ${ }^{227}$ Die Kartause St. Margarethental bildete damit einen wichtigen Knotenpunkt innerhalb der ,geistigen Region“ des Rheingebiets, die nach Hamm durch die „symbiotische Wechselbeziehung zwischen Humanismus und Frömmigkeitstheologie“ gekennzeichnet war. ${ }^{228}$

Vor diesem Hintergrund stellt sich Mosers Crinale-Adaptation als Auseinandersetzung zwischen zwei einander widerstreitenden Übersetzungsprinzipien dar: Dem Kartäuser Ludwig Moser, der sich dem klösterlichen Demutsideal und damit einer wortgetreuen, nichts ,Eigenes“ hinzufügenden Übertragung in die Volkssprache verpflichtet fühlt, tritt in Sant Bernarts Rosenkrantz der Dichter Ludwig Moser entgegen, der nach eigenem poetischen Ausdruck drängt. Die Konkurrenz von monastischer und humanistischer Liedübersetzung, die sich im Vergleich von Mosers und Brants Adaptationen des Fronleichnamshymnus Pange lingua offenbart, ${ }^{229}$ wird so in Mosers Mariengruß hineingetragen.

\section{Literaturverzeichnis}

Albrecht, Jörn: Invarianz, Äquivalenz, Adäquatheit. In: Übersetzungswissenschaft. Ergebnisse und Perspektiven. Fs. für Wolfram Wilss zum 65. Geburtstag. Hg. von Reiner Arntz, Gisela Thome. Tübingen 1990 (Tübinger Beiträge zur Linguistik 354), S. 71-81.

Appelhans, Peter: Untersuchungen zur spätmittelalterlichen Mariendichtung. Die rhythmischen mittelhochdeutschen Mariengrüße. Heidelberg 1970.

Binz, Gustav: Die deutschen Handschriften der Öffentlichen Bibliothek der Universität Basel. Bd. 1: Die Handschriften der Abteilung A. Basel 1907.

224 Vgl. Rüthing, S. 35.

225 Vgl. Wilhelmi: Humanistische Gelehrsamkeit, S. 22.

226 Vgl. ebd., S. 23 f.

227 Vgl. oben, Abschnitt 2, S. $229 \mathrm{f}$.

228 Hamm, S. 32. Zum Begriff der ,geistigen Region` vgl. ebd., S. 8-10.

229 Vgl. oben, Abschnitt 5.5, S. 261 f. 
Blüm, Hubertus Maria: Ursprung und Geschichte der Ordensstatuten der Kartäuser. In: Die Kartäuser. Der Orden der schweigenden Mönche. Hg. von Marijan Zadnikar in Verbindung mit Adam Wienand. Köln 1983, S. 38-49.

Brant, Sebastian: Das Narrenschiff. Studienausgabe. Mit allen 114 Holzschnitten des Drucks Basel 1494. Hg. von Joachim Knape. Stuttgart 2005 (Reclams Universal-Bibliothek 18333).

Brant, Sebastian: Kleine Texte. Hg. von Thomas Wilhelmi. Bd. 1.1. Stuttgart - Bad Cannstatt 1998 (Arbeiten und Editionen zur Mittleren Deutschen Literatur, N. F. 3.1.1).

Brant, Sebastian: Kleine Texte. Hg. von Thomas Wilhelmi. Bd. 1.2. Stuttgart - Bad Cannstatt 1998 (Arbeiten und Editionen zur Mittleren Deutschen Literatur, N. F. 3.1.2).

Brant, Sebastian: Kleine Texte. Noten zur Edition von Thomas Wilhelmi. Bd. 2. Stuttgart - Bad Cannstatt 1998 (Arbeiten und Editionen zur Mittleren Deutschen Literatur, N. F. 3.2).

Brinkmann, Henning: Ave praeclara maris stella in deutscher Wiedergabe. Zur Geschichte einer Rezeption. In: Studien zur deutschen Literatur und Sprache des Mittelalters. Fs. für Hugo Moser zum 65. Geburtstag. Hg. von Werner Besch u. a. Berlin 1974, S. 8-30.

Bumke, Joachim: Die vier Fassungen der ,Nibelungenklage؛: Untersuchungen zur Überlieferungsgeschichte und Textkritik der höfischen Epik im 13. Jahrhundert. Berlin, New York 1996 (Quellen und Forschungen zur Literatur- und Kulturgeschichte, N. F. 8).

Burckhardt, Max: Bibliotheksaufbau, Bücherbesitz und Leserschaft im spätmittelalterlichen Basel. In: Studien zum städtischen Bildungswesen des späten Mittelalters und der frühen Neuzeit. Bericht über Kolloquien der Kommission zur Erforschung der Kultur des Spätmittelalters 1978 bis 1981. Hg. von Bernd Moeller, Hans Patze, Karl Stackmann. Redigiert von Ludger Grenzmann. Göttingen 1983 (Abhandlungen der Akademie der Wissenschaften in Göttingen, Philologisch-Historische Klasse, Dritte Folge 137), S. 33-52.

Burckhardt, Max: Die Inkunabeln aus der Bibliothek des Johannes de Lapide. In: Für Christoph Vischer, Direktor der Basler Universitätsbibliothek 1959-1973. Von seinen Mitarbeitern. Basel 1973, S. 15-75.

Der ewigen wiszheit betbüchlin. Basel: Jakob von Pforzheim für Marx Werdemüller von Zürich, 1518. http://mdz-nbn-resolving.de/urn:nbn:de:bvb:12-bsb10997563-5 (11. September 2019).

Die Amerbachkorrespondenz. Im Auftrag der Kommission für die Öffentliche Bibliothek der Universität Basel bearb. und hg. von Alfred Hartmann. Bd. 1: Die Briefe aus der Zeit Johann Amerbachs 1481-1513. Basel 1942.

Die Chroniken des Karthäuser Klosters in Klein-Basel. 1401-1532. II. Continuatio chronicorum Carthusiae in Basilea minori, auctore fratre Georgio Carpentarii de Brugg, eiusdem domus monacho professo. 1480-1526. In: Basler Chroniken. Hg. von der Historischen Gesellschaft in Basel. Bd. 1. Hg. von Wilhelm Vischer und Alfred Stern unter Mitwirkung von Moriz Heyne. Leipzig 1872, S. 307-356.

Gilomen-Schenkel, Elsanne: Basel, St. Margarethental. In: Les Chartreux en Suisse. Hg. von Bernard Andenmatten. Basel 2006 (Helvetia Sacra III: Les Ordres suivant la Règle de Saint-Benoît 4), S. 57-86.

Gilomen-Schenkel, Elsanne: Bücher von Jakob Louber und Johannes Amerbach für die Bibliothek der Basler Kartause. In: Basler Zeitschrift für Geschichte und Altertumskunde 108 (2008), S. 13-37.

Gilomen-Schenkel, Elsanne: Die Kartause in Basel - Porträt eines städtischen Klosters. In: Kloster und Stadt am südlichen Oberrhein im späten Mittelalter und in der frühen Neuzeit. Hg. von Heinz Krieg. Schopfheim 2011 (Das Markgräflerland 2011,2), S. 140-153. 
Glassner, Christine: Stift Melk und die Melker Reform im 15. Jahrhundert. In: Die benediktinische Klosterreform im 15. Jahrhundert. Hg. von Franz Xaver Bischof, Martin Thurner. Berlin 2013 (Veröffentlichungen des Grabmann-Institutes zur Erforschung der mittelalterlichen Theologie und Philosophie 56), S. 75-91.

Groiss, Albert: Spätmittelalterliche Lebensformen der Benediktiner von der Melker Observanz vor dem Hintergrund ihrer Bräuche. Ein darstellender Kommentar zum Caeremoniale Mellicense des Jahres 1460. Münster 1999 (Beiträge zur Geschichte des alten Mönchtums und des Benediktinertums 46).

Günthart, Romy: Deutschsprachige Literatur im frühen Basler Buchdruck (ca. 1470-1510). Münster u. a. 2007 (Studien und Texte zum Mittelalter und zur frühen Neuzeit 11).

Haeller, Walther-Hugo: Studien zu Ludwig Moser, Kartäuser-Mönch in Basel. Freiburg/Schweiz 1967.

Halporn, Barbara: The Carthusian Library at Basel. In: The Library Quarterly 54,3 (1984), S. 223-244.

Hamm, Berndt: Der Oberrhein als geistige Region von 1450 bis 1520. In: Basel als Zentrum des geistigen Austauschs in der frühen Reformationszeit. Hg. von Christine Christ-von Wedel, Sven Grosse, Berndt Hamm. Tübingen 2014, S. 3-50.

Heinz, Andreas: Art. ,Rosenkranz. I. Begriff. III. Historisch.` In: LThK 8 (1999), Sp. 1302 (I.), Sp. 1303-1305 (III.).

Henkel, Nikolaus: Zu Text und Melodie von Brants ,Rosarium‘. Überlieferung und Textgebrauch. In: Sebastien Brant: son époque et la ,Nef des Fols'. Actes du colloque international, Strasbourg 10./11.3.1994. Straßburg 1995 (Collection Recherches Germaniques 5), S. $173-187$.

Honemann, Volker: Deutsche Literatur in der Laienbibliothek der Basler Kartause 1480-1520. Habil. masch. Berlin 1982.

Jacobus van Gruytrode: Speculum aureum animae peccatricis, deutsch, etc. Übers. Ludwig Moser. Basel: [Johannes Amerbach], 1497. Digitalisate (Hauptteil und Anhang): https:// doi.org/10.3931/e-rara-16322 (9. September 2019); https://doi.org/10.3931/e-rara-15157 (9. September 2019).

Janota, Johannes: Studien zu Funktion und Typus des deutschen geistlichen Liedes im Mittelalter. München 1968 (MTU 23).

Kleineidam, Erich: Die Spiritualität der Kartäuser im Spiegel der Erfurter Kartäuser-Bibliothek. In: Die Kartäuser. Der Orden der schweigenden Mönche. Hg. von Marijan Zadnikar in Verbindung mit Adam Wienand. Köln 1983, S. 185-202.

Klinkhammer, Karl Joseph: Adolf von Essen und seine Werke. Der Rosenkranz in der geschichtlichen Situation seiner Entstehung und in seinem bleibenden Anliegen. Eine Quellenforschung. Frankfurt a. M. 1972 (Frankfurter Theologische Studien 13).

Knape, Joachim: Sebastian Brant als Lieddichter. In: Lied im deutschen Mittelalter. Überlieferung, Typen, Gebrauch. Chiemsee-Colloquium 1991. Hg. von Cyril Edwards, Ernst Hellgardt, Norbert H. Ott. Tübingen 1996, S. 309-333.

Kraß, Andreas: ,Ave maris stella' und ,Ave praeclara maris stella' in einem deutschen Mariengebetbuch. In: ZfdA 140 (2011), S. 190-199.

Kraß, Andreas: ,Ich gruess dich gerne'. Aspekte historischer Intertextualität am Beispiel von gereimten Übersetzungen der Mariensequenz ,Ave praeclara maris stella‘ in Mittelalter und Früher Neuzeit. In: Grundlagen, Forschungen, Editionen und Materialien zur deutschen Literatur und Sprache des Mittelalters und der Frühen Neuzeit. Hg. von Rudolf 
Bentzinger, Ulrich-Dieter Oppitz, Jürgen Wolf. Stuttgart 2013 (ZfdA, Beiheft 18), S. 301314.

Kraß, Andreas: Spielräume mittelalterlichen Übersetzens. Zu Bearbeitungen der

Mariensequenz Stabat mater dolorosa. In: Übersetzen im Mittelalter. Cambridger Kolloquium 1994. Hg. von Joachim Heinzle, L. Peter Johnson, Gisela Vollmann-Profe. Berlin 1996 (Wolfram-Studien 14), S. 87-108.

Kraume, Herbert: Art. ,Moser, Ludwig‘. In: VL² 6 (1987), Sp. 705-710.

Lentes, Thomas: Bildertotale des Heils. Himmlischer Rosenkranz und Gregorsmesse. In: Der Rosenkranz. Andacht, Geschichte, Kunst. Hg. von Urs-Beat Frei, Fredy Bühler. Bern 2003, S. 68-87.

Marie Spiegel Sant Bonauenture (Speculum marie). Übers. Ludwig Moser. 2 Bde. Basel: Michael Furter, 1506 und 1507.

Matter, Stefan: Mittelhochdeutsche Tagzeitentexte im Spannungsfeld von Liturgie und Privatandacht. Zu Formen des Laienstundengebetes im deutschsprachigen Mittelalter. In: Lehren, Lernen und Bilden in der deutschen Literatur des Mittelalters. XXIII. Anglo-German Colloquium, Nottingham 2013. Hg. von Henrike Lähnemann, Nicola McLelland, Nine Miedema. Tübingen 2017, S. 171-184.

Nemes, Balázs J.: Das lyrische CEuvre von Heinrich Laufenberg in der Überlieferung des 15. Jahrhunderts: Untersuchungen und Editionen. Stuttgart 2015.

Niederkorn-Bruck, Meta: Amt, Lehramt, Charisma. Die Bedeutung von prudentia, discretio und Norm zur Zeit der Ersten Melker Reform. In: Between Creativity and Norm-Making. Tensions in the Later Middle Ages and the Early Modern Era. Hg. von Sigrid Müller, Cornelia Schweiger. Leiden, Boston 2013 (Studies in Medieval and Reformation Traditions 165), S. 77-101.

Rajewski, Sister Mary Alvarita: Sebastian Brant. Studies in Religious Aspects of His Life and Works with Special Reference to the Varia Carmina. Washington, D. C. 1944 (The Catholic University of America: Studies in German 20).

Richardson, Nicholas: Prudentius' Hymns for Hours and Seasons. Liber Cathemerinon. London, New York 2016 (Routledge Later Latin Poetry).

Rothenberger, Eva: ,Ave praeclara maris stella‘. Poetische und liturgische Transformationen der Mariensequenz im deutschen Mittelalter. Berlin, Boston 2019 (Liturgie und Volkssprache 2).

Ruh, Kurt: Bonaventura deutsch. Ein Beitrag zur deutschen Franziskaner-Mystik und -Scholastik. Bern 1956 (Bibliotheca Germanica 7).

Ruh, Kurt: ,Der goldene Spiegel der armen sündigen Seele‘. In: VL² 3 (1981), Sp. $91 \mathrm{f}$.

Rüthing, Heinrich: Die Kartäuser und die spätmittelalterlichen Ordensreformen. In: Reformbemühungen und Observanzbestrebungen im spätmittelalterlichen Ordenswesen. Hg. von Kaspar Elm (Berliner Historische Studien 14; Ordensstudien VI), S. 35-58.

Schmidt, Karl: Einige deutsche Gedichte von Sebastian Brant. In: Alsatia. Neue Beiträge zur elsässischen Landes-, Rechts- und Sittengeschichte, Sage, Sprache und Literatur. 18731874. Hg. von August Stöber. Colmar 1875, S. 43-60.

Sexauer, Wolfram D.: Frühneuhochdeutsche Schriften in Kartäuserbibliotheken. Untersuchungen zur Pflege der volkssprachlichen Literatur in Kartäuserklöstern des oberdeutschen Raums bis zum Einsetzen der Reformation. Frankfurt a. M. 1978 (Europäische Hochschulschriften: Reihe 1, Deutsche Literatur und Germanistik 247). 
Statuta ordinis cartusiensis a domno Guigone priore cartusie edita. Basel: Johannes Amerbach, 1510. http://data.onb.ac.at/rep/1083172 A (11. September 2019).

Stieglecker, Roland: Die Renaissance eines Heiligen. Sebastian Brant und Onuphrius eremita. Wiesbaden 2001 (Gratia. Bamberger Schriften zur Renaissanceforschung 37).

The Hymns of Prudentius. Translated by R. Martin Pope. London 1905. https://www.gutenberg. org/files/14959/14959-h/14959-h.htm (20. September 2019).

von Scarpatetti, Beat Matthias: Katalog der datierten Handschriften in der Schweiz in lateinischer Schrift vom Anfang des Mittelalters bis 1550. Die Handschriften der Bibliotheken von Aarau, Appenzell und Basel. Bd. 1: Text. Dietikon-Zürich 1977.

Wachinger, Burghart: Notizen zu den Liedern Heinrich Laufenbergs. In: Ders.: Lieder und Liederbücher. Gesammelte Aufsätze zur mittelhochdeutschen Lyrik. Berlin, New York 2011, S. 329-361.

Wegener, Lydia, Franziska Lallinger, Arrate Cano Martín-Lara: Transformation und Destruktion. Formen der volkssprachlichen Aneignung des Salve regina im fünfzehnten und sechzehnten Jahrhundert. In: Maria in Hymnus und Sequenz. Interdisziplinäre mediävistische Perspektiven. Hg. von Eva Rothenberger, Lydia Wegener. Berlin, Boston 2017 (Liturgie und Volkssprache 1), S. 395-450.

Wilhelmi, Thomas: Humanistische Gelehrsamkeit im Umkreis der Basler Kartause. In: Bücher, Bibliotheken und Schriftkultur der Kartäuser. Festgabe zum 65. Geburtstag von Edward Potkowski. Hg. von Sönke Lorenz. Stuttgart 2002 (Contubernium 59), S. 21-27.

Worstbrock, Franz Josef: Art. ,Konrad von Haimburg (von Gaming, Conradus Gemnicensis)‘. In: $\mathrm{VL}^{2} 5$ (1985), Sp. 182-189. 